\title{
The 2009-2010 Arctic stratospheric winter - general evolution, mountain waves and predictability of an operational weather forecast model
}

\author{
A. Dörnbrack ${ }^{1}$, M. C. Pitts ${ }^{2}$, L. R. Poole ${ }^{3}$, Y. J. Orsolini ${ }^{4}$, K. Nishii ${ }^{5}$, and H. Nakamura ${ }^{5}$ \\ ${ }^{1}$ Institut für Physik der Atmosphäre, DLR Oberpfaffenhofen, 82230 Oberpfaffenhofen, Germany \\ ${ }^{2}$ NASA Langley Research Center, Hampton, Virginia 23681, USA \\ ${ }^{3}$ Science Systems and Applications, Incorporated, Hampton, Virginia 23666, USA \\ ${ }^{4}$ Norwegian Institute for Air Research, Kjeller, Norway \\ ${ }^{5}$ Research Center for Advanced Science and Technology, University of Tokyo, Tokyo, Japan
}

Correspondence to: A. Dörnbrack (andreas.doernbrack@dlr.de)

Received: 24 October 2011 - Published in Atmos. Chem. Phys. Discuss.: 9 December 2011

Revised: 20 March 2012 - Accepted: 21 March 2012 - Published: 19 April 2012

\begin{abstract}
The relatively warm 2009-2010 Arctic winter was an exceptional one as the North Atlantic Oscillation index attained persistent extreme negative values. Here, selected aspects of the Arctic stratosphere during this winter inspired by the analysis of the international field experiment RECONCILE are presented. First of all, and as a kind of reference, the evolution of the polar vortex in its different phases is documented. Special emphasis is put on explaining the formation of the exceptionally cold vortex in mid winter after a sequence of stratospheric disturbances which were caused by upward propagating planetary waves. A major sudden stratospheric warming (SSW) occurring near the end of January 2010 concluded the anomalous cold vortex period. Wave ice polar stratospheric clouds were frequently observed by spaceborne remote-sensing instruments over the Arctic during the cold period in January 2010. Here, one such case observed over Greenland is analysed in more detail and an attempt is made to correlate flow information of an operational numerical weather prediction model to the magnitude of the mountain-wave induced temperature fluctuations. Finally, it is shown that the forecasts of the ECMWF ensemble prediction system for the onset of the major SSW were very skilful and the ensemble spread was very small. However, the ensemble spread increased dramatically after the major SSW, displaying the strong non-linearity and internal variability involved in the SSW event.
\end{abstract}

\section{Introduction}

The purpose of this study is to present a brief overview of the evolution of the Arctic stratospheric polar vortex during the 2009-2010 winter, to discuss the quality of the stratospheric forecasts of the European Centre of Medium Range Weather Forecasts (ECMWF) numerical weather prediction model IFS $^{1}$, and to analyse mountain-wave induced stratospheric temperature anomalies over Greenland. During the 20092010 Arctic winter, airborne observations in the stratosphere were conducted during the international RECONCILE ${ }^{2}$ campaign. This four-year research project was implemented by the European Union for comprehensive and detailed investigations of key processes governing Arctic ozone depletion. As a main research tool, the Russian high-altitude research

\footnotetext{
${ }^{1}$ The Integrated Forecast System (IFS) - see http://www.ecmwf. $\mathrm{int} / \mathrm{research} / \mathrm{ifsdocs}$ - is a primitive equation model based on a twotime-level, semi-implicit, semi-Lagrangian spectral transformation dynamical core with a linear Gaussian transform grid and a triangular truncation. A finite element discretization is employed in the vertical direction, see also Hortal (2002) and Untch and Hortal (2004).

2 "Reconciliation of essential process parameters for an enhanced predictability of Arctic stratospheric ozone loss and its climate interactions" - a multinational project funded under the European Commission 7th Framework Programme; see https://www. fp7-reconcile.eu.
} 
aircraft M55 GEOPHYSIKA ${ }^{3}$ (Stefanutti et al., 1999) was deployed in two distinct phases, with eight flights from 1728 January 2010 and four flights in the second phase from 27 February-5 March 2010. For both phases, the aircraft was based in Kiruna, Sweden. The GEOPHYSIKA was equipped with sophisticated in-situ and remote-sensing instruments to probe the chemical composition and particle distributions and properties in the polar stratosphere. Additionally, during this winter spaceborne CALIPSO (Cloud-Aerosol Lidar and Infrared Pathfinder Satellite Observations) measurements of polar stratospheric clouds (PSCs) revealed remarkable properties in cloud extent and structure; see e.g. Pitts et al. (2011), Koshrawi et al. (2011) and other papers, e.g. Kuttippurath et al. (2010).

The northern polar vortex exhibits remarkable interannual variability. During the 2009-2010 winter, the sequence of a cold mid-winter vortex followed by a major sudden stratospheric warming (SSW) near the end of January 2010 led to a variety of interesting phenomena during the two field phases of RECONCILE. From a dynamical viewpoint, probably the most interesting question of this stratospheric winter is why such a strong and persistent polar vortex evolved from mid December 2009 until the end of January 2010 although many disturbances occurred earlier in November and December 2009 (e.g. Wang and Chen, 2010; Cohen et al., 2010). This question will be answered by investigating the evolution of the Western Pacific teleconnection patterns as described by Orsolini et al. (2009) and Nishii et al. (2010). We will investigate the subsequent major SSW, classify its development according to the zonal-mean diagnostics developed by Charlton and Polvani (2007, hereafter CP07) as a displacement or splitting type of warming, and, finally, answer the question: was the 2009-2010 Arctic stratospheric winter really unusually cold?

A refined classification of the CALIPSO observations by Pitts et al. (2011) enabled the identification of wave ice PSCs. Especially, during January 2010, wave ice PSCs were frequently observed over and downstream of orographic obstacles in Greenland, northern Scandinavia, and Novaya Zemlya. Pitts et al. (2011) juxtaposed CALIPSO wave ice observations with a flow diagnostic derived from operational ECWMF analyses, namely horizontal divergence DIV, frequently used as a dynamical indicator of internal gravity waves, see for example Plougonvon et al. (2003). For a selected time period in January 2010, reasonable correspondence was found by Pitts et al. (2011) between wave ice PSC detections and local divergence/convergence whose magnitude exceeds a certain threshold. Here, we explore one case of CALIPSO mountain-wave induced PSC observations in more detail and investigate the quantitative relationship between DIV magnitude and stratospheric temperature anomalies. Furthermore, forward and backward trajectories are cal-

\footnotetext{
${ }^{3}$ There exists an old web page about the M55 GEOPHYSIKA: http://www.geophysica-eeig.eu/index.php.
}

culated to demonstrate the long-distance impact local wave sources can have on the temperature history of air parcels.

For the first time, and in addition to the familiar usage of deterministic forecasts, the operational forecasts of the ECMWF ensemble prediction system (EPS) are analysed to provide quantitative measures of the reliability of the stratospheric forecasts. As stratospheric research flights usually require meticulous planning and preparation several days in advance, we assess the quality of the $120 \mathrm{~h}$ and $240 \mathrm{~h}$ forecasts by all of the 50 ensemble members.

The paper is divided into five parts. After this Introduction, the methodology and the data sources are explained. Section 3 deals with thermodynamic aspects of the vortex evolution and the quality of the ECWMF forecasts. Section 4 presents the investigation of a particular mountain wave period at the beginning of the very cold vortex period, and the final Sect. 5 presents conclusions.

\section{Methodology}

\subsection{Meteorological analyses and forecasts}

In this study, different datasets are used. The "truth" is represented by either operational analysis or by ERA-Interim reanalysis data (Dee et al., 2011) ${ }^{4}$. Moreover, short- and medium-range forecasts from two different sources are used: operational high-resolution deterministic forecasts and the lower-resolution control forecasts from the ECMWF ensemble prediction system. In addition to the control run, the EPS consists of 50 differently initialised members. During the 2009-2010 winter (on 26 January 2010, to be precise), ECMWF upgraded the horizontal resolutions of its deterministic forecast and data assimilation systems and of the EPS. The resolution of the deterministic model was increased from $T_{\mathrm{L}} 799 \mathrm{~L} 91\left(\sim 25 \mathrm{~km}\right.$ grid, $\left.p_{\text {TOP }}=0.01 \mathrm{hPa}\right)$ to $T_{\mathrm{L}} 1279 \mathrm{~L} 91\left(\sim 16 \mathrm{~km}, p_{\text {TOP }}=0.01 \mathrm{hPa}\right)$; the EPS resolution changed from $T_{\mathrm{L}} 399 \mathrm{~L} 62\left(\sim 56 \mathrm{~km}, p_{\mathrm{TOP}}=5 \mathrm{hPa}\right)$ to $T_{\mathrm{L}} 639$ L62 $\left(\sim 32 \mathrm{~km}, p_{\text {TOP }}=5 \mathrm{hPa}\right)$ for the first 10 days of the forecasts. For further details on how the operational forecasting system evolved before this update, see, for example, Tables I and II in Jung and Leutbecher (2007) or consult the ECMWF web site (http://www.ecmwf.int). In addition to the ECMWF data, the analysis of the Western Pacific (WP) index was performed using the reanalysis data of the Japan Meteorological Agency (JMA) and the Central Research Institute of Electric Power Industry (CRIEPI), JRA25 reanalysis, see Onogi et al. (2007).

\footnotetext{
${ }^{4}$ ERA-Interim is the latest ECMWF global atmospheric reanalysis of the period 1989 to the present. Information on the resolution, the data assimilation system, the observations and the boundary forcing of the ECMWF-Interim reanalysis project can be found at http://www.ecmwf.int/research/era/do/get/era-interim.
} 


\subsection{Measures for gravity wave activity}

Locations of stratospheric gravity wave activity are derived from the ECMWF horizontal wind divergence (DIV) at $30 \mathrm{hPa}$. As discussed in Plougonven et al. (2003), the identified waves may not have the correct wavelengths and frequencies (due to the limited spatial and horizontal resolution), but the time and location of the waves as well as their phase orientation are expected to be relevant for studying their generation and propagation processes. In contrast to earlier studies using DIV to provide some qualitative indications of the horizontal structure of the waves, we attempt to relate the magnitude of the horizontal wind divergence to the temperature fluctuations relevant for the generation of PSCs, see Sect. 3.3. As an additional diagnostic tool for determining the temperature fluctuations due to the adiabatic cooling and warming in mountain-wave induced temperature anomalies, we analyze ensembles of trajectories calculated with the Lagrangian trajectory model LAGRANTO (Wernli and Davies, 1997).

\subsection{CALIPSO Data}

For the case study provided in Sect. 3.3, spaceborne lidar measurements from CALIPSO provide the different PSC compositions observed along the selected orbits. The primary instrument on CALIPSO is a lidar (CALIOP, or CloudAerosol Lidar with Orthogonal Polarization) that measures backscatter at wavelengths of $1064 \mathrm{~nm}$ and $532 \mathrm{~nm}$, with the 532-nm signal separated into orthogonal polarization components parallel and perpendicular to the polarization plane of the outgoing laser beam. A description of CALIOP and its on-orbit performance can be found in Hunt et al. (2009), and details on calibration of the CALIOP data are provided by Powell et al. (2009). CALIOP has proven to be an excellent system for observing PSCs (Pitts et al., 2007, 2009, 2011).

The CALIPSO PSC algorithm as defined by Pitts et al. (2009) defined four CALIPSO PSC composition classes: supercooled ternary solution (STS), water ice, and two classes (Mix 1 and Mix 2) of liquid/nitric acid trihydrate (NAT) mixtures. Mix 1 denotes mixtures with very low NAT number densities (from about $3 \times 10^{-4}$ to $10^{-3} \mathrm{~cm}^{-3}$ ), while Mix 2 denotes mixtures with higher $\left(>10^{-3} \mathrm{~cm}^{-3}\right)$ NAT number densities. Prompted by CALIOP observations during the recent winters, Pitts et al. (2011) defined two new PSC classes. Besides one additional NAT PSC class as referred to as Mix 2 enhanced, Pitts et al. (2011) found that intense mountain-wave induced PSCs can be distinguished as a subset of CALIPSO ice PSCs through their distinct optical signature in $R_{532}$, the ratio of total to molecular backscatter at $532 \mathrm{~nm}$, and the lidar colour ratio, the ratio of 1064 $\mathrm{nm}$ particulate backscatter to $532-\mathrm{nm}$ particulate backscatter. In general, lidar colour ratio is an indicator of the particle size; cirrus and tropospheric clouds have colour ratios of around 1, indicating large particles, while smaller aerosol particles have lower colour ratios (Liu et al., 2004). Over most of the ice PSC domain, the maximum number of observations occurs at colour ratios from 0.75 to 1.0 , indicating large particles. But for ice PSCs with $1 / R_{532}<0.02$, the maximum in the number of observations shifts abruptly to colour ratios of 0.25 to 0.435 (see Fig. 2 in Pitts et al., 2011). As shown by Pitts et al. (2011), this behaviour is consistent with mountain-wave induced PSCs having high ice particle number densities $(\sim 100 \%$ ice activation from the background aerosol) but relatively small particles (1-1.5 $\mu \mathrm{m}$ radius). Therefore, and because of their correspondence with the location of a dynamical indicator of mountain waves, the CALIPSO ice cloud observations with $1 / R_{532}<0.02$ are interpreted as mountain wave PSCs. Note that the CALIPSO wave ice PSC class is not all-inclusive; other CALIPSO ice PSC observations may be associated with mountain waves, but do not meet the strict $\left(1 / R_{532}<0.02\right)$ wave ice identification criterion, e.g. observations immediately upwind or downwind of the location of peak backscatter.

\section{Results}

\subsection{Polar vortex evolution}

The temporal evolution of the minimum temperature $T_{\mathrm{MIN}}$ at the $50 \mathrm{hPa}$ pressure surface between $65^{\circ} \mathrm{N}$ and $90^{\circ} \mathrm{N}$ during the 2009-2010 Arctic winter is compared to the recent 21yr climatology in Fig. 1. Cooling of the Arctic polar vortex generally followed the 21-yr ECMWF climatological mean through mid November 2009, when $T_{\text {MIN }}$ had dropped to about $200 \mathrm{~K}$ (Fig. 1). From mid November until mid December $2009, T_{\text {MIN }}$ was well above the climatological mean. This period was characterized by downward propagating temperature anomalies in the stratosphere (see Fig. 4 in Wang and Chen, 2010 and Sect. 3.2). As a consequence of these disturbances, the polar vortex split into two unequally strong lobes during the first ten days of December. Figure 2a, b illustrates the corresponding flow and temperature structure of the polar vortex. The associated minor warming prevented a further decline of $T_{\mathrm{MIN}}$, resulting in the observed $T_{\mathrm{MIN}}$ values above the climatological mean. The stronger and colder vortex lobe located over the Canadian sector of the Arctic survived this early warming event, recovered and cooled gradually through mid-January 2010 . There was a significant drop in $T_{\text {MIN }}$ below $T_{\mathrm{NAT}}$ and $T_{\mathrm{FROST}}$ during this period, to values as much as $9 \mathrm{~K}$ below the climatological mean (Fig. 1). Typical flow and temperature fields from this exceptionally cold period are shown in Fig. 2c, d, depicting a coherent polar vortex centred near the North Pole. An analysis for the physical mechanisms leading to this period is presented in Sect. 3.2.

During the second half of January 2010, a planetary wavenumber-one event displaced the polar vortex towards the European sector of the Arctic (see Fig. 3a, b). This major warming event marked the start of the gradual break-up of the polar 


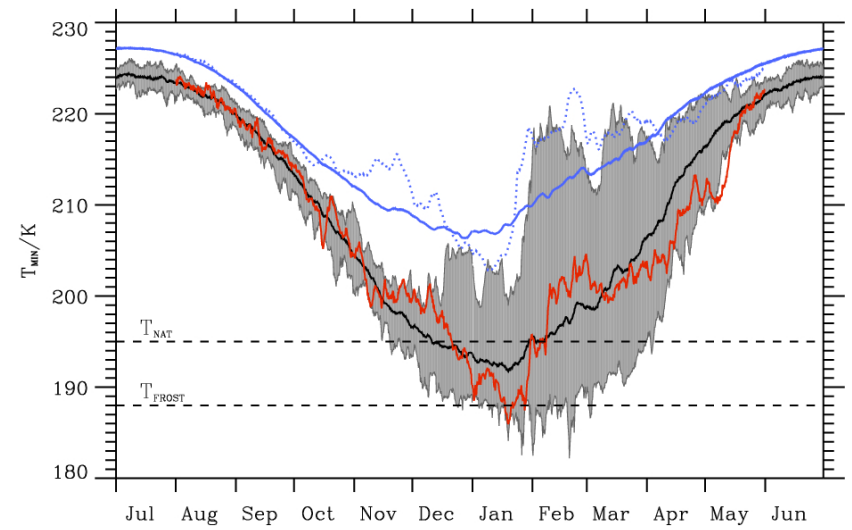

Fig. 1. Minimum temperatures $T_{\mathrm{MIN}}(\mathrm{K})$ between 65 to $90^{\circ} \mathrm{N}$ at the $50 \mathrm{hPa}$ pressure surface: Black line denotes the mean value from 1989-2009, the red line the $T_{\mathrm{MIN}}$ evolution from August 2009 through May 2010; shaded area encompasses the minimum/maximum $T_{\text {MIN }}$ between 1989 and 2009. Blue solid line: climatological mean polar cap $\left(50\right.$ to $\left.90^{\circ} \mathrm{N}\right)$ temperature $T_{\text {POLAR CAP }}$; dotted blue line: mean polar cap temperature from August 2009 through May 2010. Source: ECMWF reanalyses interim (ERAInterim) data provided at 6 hourly temporal resolutions, see: http: //www.ecmwf.int. The PSC formation temperatures $T_{\mathrm{NAT}}$ and $T_{\text {FROST }}$ are calculated assuming volume mixing ratios of $5 \mathrm{ppm}$ for water vapour and $10 \mathrm{ppb}$ for nitric acid trihydrate (NAT); Hanson and Mauersberger (1988).

vortex. Although the vortex rapidly lost its symmetry and the cold region progressively shifted away from the vortex centre (resulting in an increasing baroclinicity and susceptibility for instabilities), $T_{\mathrm{MIN}}$ inside the vortex remained below the climatological mean until the end of January 2010 at $50 \mathrm{hPa}$ (Fig. 1). However, the intense and long-lasting disturbance of the polar vortex through the planetary wave activity resulted in a continuous warming in February 2010. Figure 3c, d depicts the stratospheric flow and temperature fields in early February 2010, several days before the final vortex break-up.

The mean polar cap temperature $T_{\text {POLARCAP }}$ in 2009 2010 (blue lines in Fig. 1) evolved in a qualitatively similar evolution as did $T_{\mathrm{MIN}}$. However, and in contrast to $T_{\mathrm{MIN}}$, $T_{\text {POLARCAP indicated the onset of the warming earlier as a }}$ result of the vortex displacement from the pole. Furthermore, the mean polar cap temperature remained above the climatological mean for a longer period, until the end of March 2010. This means, that the Arctic stratosphere as a whole was warmer than usual, but that there were small regions within the vortex with $T_{\mathrm{MIN}}$ below the climatological mean in March 2010.

Another interesting feature during this period was the frequent occurrence of wave-like structures, discernable as undulations of the geopotential height fields in the extreme cold region over Greenland's east cost (Fig. 2c, d). The associated regional cooling resulted from the adiabatic expansion in updrafts induced by orographic gravity waves excited by
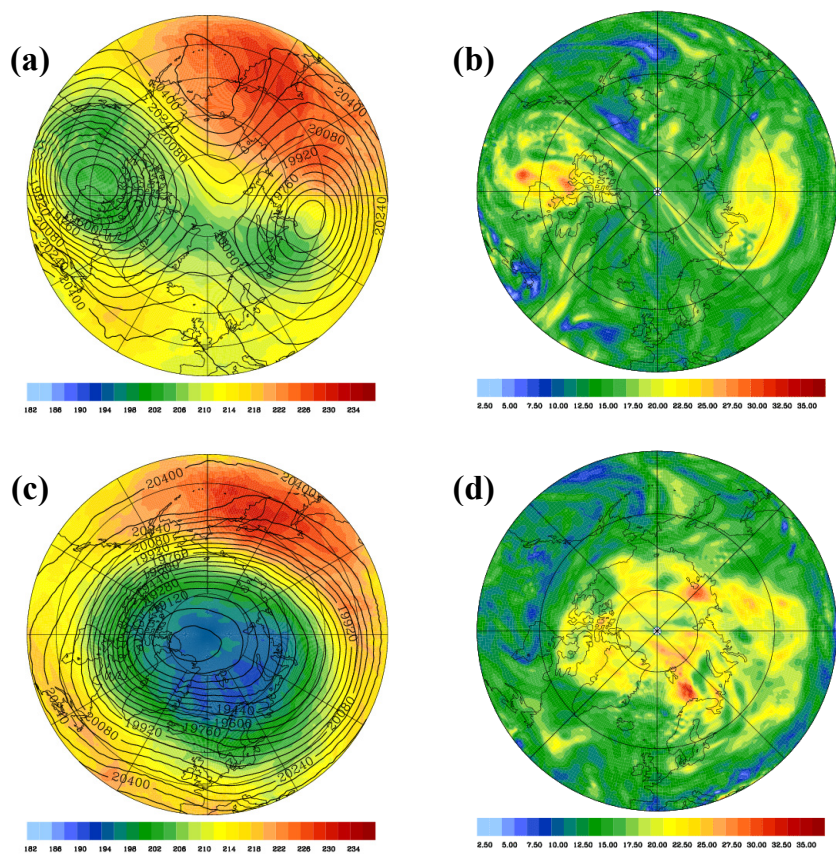

Fig. 2. Panels (a) and (c): absolute Temperature (K, colour shaded) and geopotential height (m; black contour lines) at the $50 \mathrm{hPa}$ pressure surface. Panels (b) and (d): scaled or modified potential vorticity PV $\cdot(\Theta / 420 \mathrm{~K})^{-9 / 2}$ (PVU; colour shaded) at $\Theta=425 \mathrm{~K}$ (see Lait, 1994). Operational ECMWF analyses interpolated at a regular $0.5 \times 0.5^{\circ}$ latitude/longitude grid for 10 December 2009 (a, b) and 9 January 2010 (c, d).

the flow across Greenland. A case study will be discussed in detail in Sect. 4.

According to the WMO definition ${ }^{5}$, a sudden stratospheric warming occurs when the zonal mean zonal wind at $60^{\circ} \mathrm{N}$ on the $10 \mathrm{hPa}$ pressure surface becomes easterly. The first day on which the daily zonal-mean zonal wind at $60^{\circ} \mathrm{N}$ and $10 \mathrm{hPa}$ is easterly is defined as the central date of the warming

\footnotetext{
${ }^{5}$ It must be noted that the so called WMO definition of sudden stratospheric warmings has been interpreted differently in details by different authors. Andrews et al. (1987, p. 259) writes: "It is defined somewhat arbitrarily, to be a major warming if at $10 \mathrm{mb}$ or below the zonal-mean temperature increases poleward from $60^{\circ}$ latitude and the zonal-mean zonal wind reverses. If the temperature gradient reverses there but the circulation does not, it is defined to be a minor warming.". Krüger et al. (2005) specify the North pole as the exact location where the temperature gradient $\Delta T=T_{90^{\circ} \mathrm{N}}-T_{60^{\circ} \mathrm{N}}$ has to be calculated: "Major warmings are associated with a breakdown of the polar vortex as well as a warming of the polar region and the reversal of the meridional temperature gradient between $60^{\circ}$ latitude and the Pole. The vortex breakdown is defined by the reversal of the mean zonal westerlies poleward of $60^{\circ}$ latitude into easterlies, at least down to $10 \mathrm{hPa}$." On the other hand, Limpasuvan et al. (2004) modified the criteria three ways by taking $85^{\circ} \mathrm{N}$ and adding a 5 days period for which $\Delta T=T_{85^{\circ} \mathrm{N}}-T_{60^{\circ} \mathrm{N}}$ has to be positive and shifting the latitude from 60 to $65^{\circ} \mathrm{N}$ for calculating the wind criteria: "According to the WMO definition,
} 

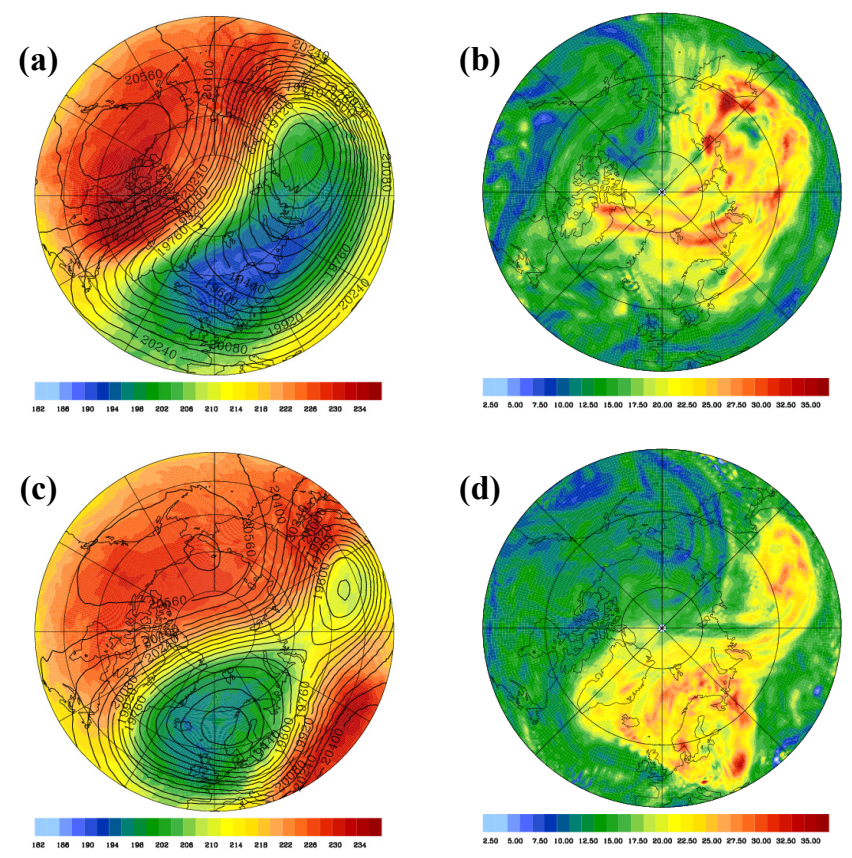

Fig. 3. Panels (a) and (c): absolute Temperature (K, colour shaded) and geopotential height (m; black contour lines) at the $50 \mathrm{hPa}$ pressure surface. Panels (b) and (d): scaled or modified potential vorticity PV $\cdot(\Theta / 420 \mathrm{~K})^{-9 / 2}$ (PVU; colour shaded) at $\Theta=425 \mathrm{~K}$ (see Lait, 1994). Operational ECMWF analyses interpolated at a regular $0.5 \times 0.5^{\circ}$ latitude/longitude grid for 24 January $2010(\mathbf{a}, \mathbf{b})$ and 5 February 2010 (c, d).

(CP07). During the Arctic winter 2009-2010, the central date was determined to be 26 January 2010 (see Fig. 4b). Additionally, the WMO definition requires that the $10 \mathrm{hPa}$ zonal-mean temperature gradient between $60^{\circ} \mathrm{N}$ and $85^{\circ} \mathrm{N}$ be positive for an event to be designated as major warming (see Limpasuvan et al., 2004, p. 2588). This condition was already satisfied exactly 5 days before the central date (see Fig. 4a). CP07 used $90^{\circ} \mathrm{N}$ as the northernmost reference latitude to calculate the meridional zonal-mean temperature gradient; conducting the same analysis with temperatures taken at this latitude does not change our results. No days within 20 days of the central date can be defined as SSW (vertical dashed lines at 15 February 2010 in Fig. 4). According to the WMO definition, the final warming occurred during the second half of February when the zonal-mean zonal wind became easterly and did not return to westerly for 10 days from 16 until 26 February 2010. This is in agreement with $T_{\mathrm{MIN}}$ and $T_{\text {POLARCAP }}$ at $50 \mathrm{hPa}$ being well above the climatological mean.

a stratospheric warming occurs when the latitudinal gradient in 10 - $\mathrm{PPa}$ zonal-mean temperatures between $85^{\circ} \mathrm{N}$ and $60^{\circ} \mathrm{N}$ is positive for more than 5 days. If the 10-hPa zonal-mean zonal wind at $65^{\circ} \mathrm{N}$ is concurrently easterly, the warming event is categorized as a "major warming"; otherwise, the warming event is categorized as "minor" (see Andrews et al., 1987)."
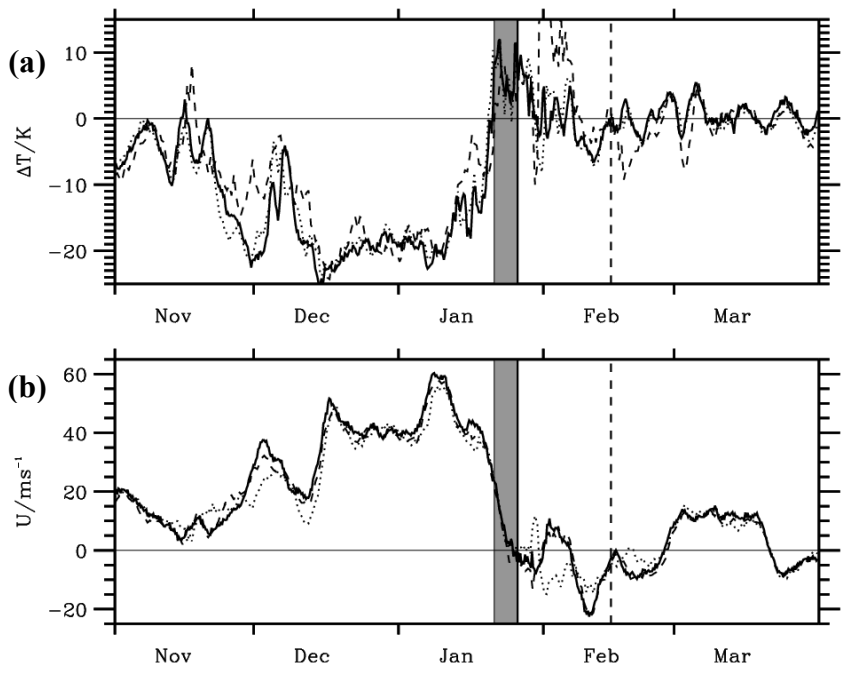

Fig. 4. Criteria of a major warming: time series of $120 \mathrm{~h}$ forecasts at $10 \mathrm{hPa}$ of the meridional temperature difference (a) and the zonally averaged zonal velocity at $60^{\circ} \mathrm{N}$ (b) for the winter 2009/2010. Results are shown for high-resolution deterministic (dotted lines) and lower-resolution EPS control forecasts (dashed lines). Also shown is the verifying operational analysis (solid lines). $\Delta T$ is computed from zonally averaged temperature differences between $85^{\circ} \mathrm{N}$ and $60^{\circ} \mathrm{N}$. The grey shaded column marks the 5 day period after the mean temperature gradient between $85^{\circ} \mathrm{N}$ and $60^{\circ} \mathrm{N}$ is positive and the thick solid line marks the central date of the major warming event on 26 January 2010. The dashed vertical line marks the end of the 20 day period after the central date of the SSW.

In addition to the operational ECMWF analyses, Fig. 4 also displays the temporal evolution of the operational deterministic and the EPS control forecasts for a lead time of $120 \mathrm{~h}$ for both of the SSW criteria. Although the operational forecasts predict the onset of the major SSW event accurately, there exist some discrepancies between the forecasts and the verifying analyses, especially after the major SSW end of January, which will be discussed in Sect. 3.3.

Based on a composite analysis, CP07 classified SSWs into vortex displacement and splitting events. Figure 5 depicts the 2009-2010 polar cap temperature anomaly $\Delta T_{\text {POLARCAP for }}$ different pressure levels in a manner analogous to Fig. 6 in CP07. Here, $\Delta T_{\text {POLARCAP is calculated as the deviation to }}$ the temporal mean of the zonally averaged $T_{\text {POLARCAP }}$ between $50^{\circ} \mathrm{N}$ and $90^{\circ} \mathrm{N}$ for the winter months DJFM. The evolution of $\Delta T_{\text {POLARCAP }}$ at $10 \mathrm{hPa}$ (black solid line in Fig. 5) corresponds qualitatively to the characteristic curve, CP07 calculated for the vortex displacement type as a composite average. During the growth phase of the anomaly,

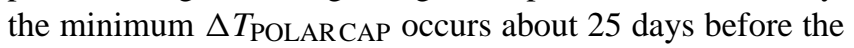
maximum $\Delta T_{\text {POLARCAP. The }} \Delta T_{\text {POLARCAP }}$ decrease in the decay phase is within $3 \mathrm{~K}$ of the values found for the vortex displacement composite of $\mathrm{CP} 07$. However, the strength of the anomaly with $\Delta T_{\text {POLARCAP }} \approx 17 \mathrm{~K}$ is about twice the values calculated by CP07. This certainly reflects the fact 


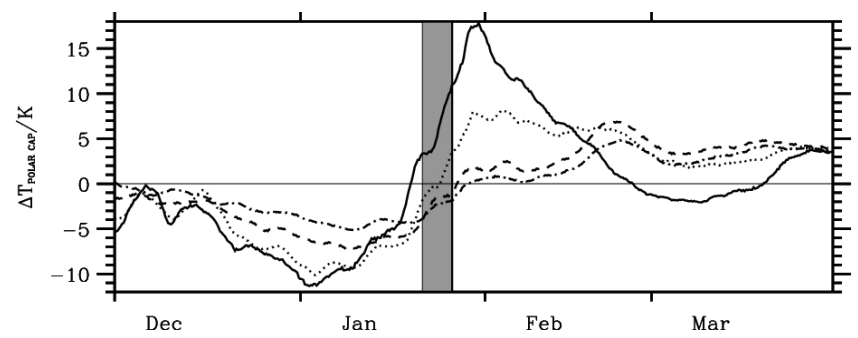

Fig. 5. Polar cap temperature $\left(50\right.$ to $\left.90^{\circ} \mathrm{N}\right)$ anomaly $\Delta T_{\text {POLARCAP }}$ at $10 \mathrm{hPa}$ (solid line), $20 \mathrm{hPa}$ (dotted line), $50 \mathrm{hPa}$ (dashed line) and $100 \mathrm{hPa}$ (dashed-dotted line) for the winter months December, January, February, and March 2009-2010. The grey shaded area mark the 5 day period after the mean temperature gradient between $85^{\circ} \mathrm{N}$ and $60^{\circ} \mathrm{N}$ is positive and the thick solid line marks the central date of the major warming event on 26 January 2010.

that the composite diagnostic of CP07 is an average over 15 events. Also astonishing is the temporal shift of the positive anomaly after the central date of the major SSW unlike in the CP07 analysis where it occurred exactly at the central date. In contrast to CP07, we do not observe an extended decay phase at lower levels (see dashed line in Fig. 5). Instead, the polar cap anomalies are amplified in the second half of February 2010. This is consistent with the splitting of the polar vortex in this time period; see the Supplement. In summary, we conclude that the SSW end of January 2010 resembles the displacement type. The eventual vortex break up into two lobes occurred in the second half of February 2010.

A climatological analysis to explore the question of whether this winter was exceptionally cold revealed the surprising result that the 2009-2010 winter was the second (third) warmest winter in the last $21 \mathrm{yr}$ at $30 \mathrm{hPa}(50 \mathrm{hPa})$, see Tables 1 and 2, respectively. Only the period from the end of December 2009 until the end of January 2010 was colder than the climatological mean. This result is also confirmed by the negative stratospheric temperature anomalies in the different winter months as shown in Fig. 6. Two pronounced cold temperature anomalies exist in December and January over Canada and the European-Asian sector, respectively. These temperature anomalies are associated with stronger than normal vortices in these regions (see negative anomalies in the geopotential height fields in Fig. 7).

\subsection{Strong vortex event of early January}

The first phase of the RECONCILE flight campaign took place from the middle to end of January 2010. In the lower stratosphere, the coldest conditions in the entire winter occurred then, in a brief period between the two strong stratospheric warming events of December and late January. We now examine in some details the origin and development of this pronounced cold vortex event. The vortex averaged temperature $T_{\text {POLARCAP }}$ at $50 \mathrm{hPa}$ was anomalously cold from late December to early January, and local temperatures fell
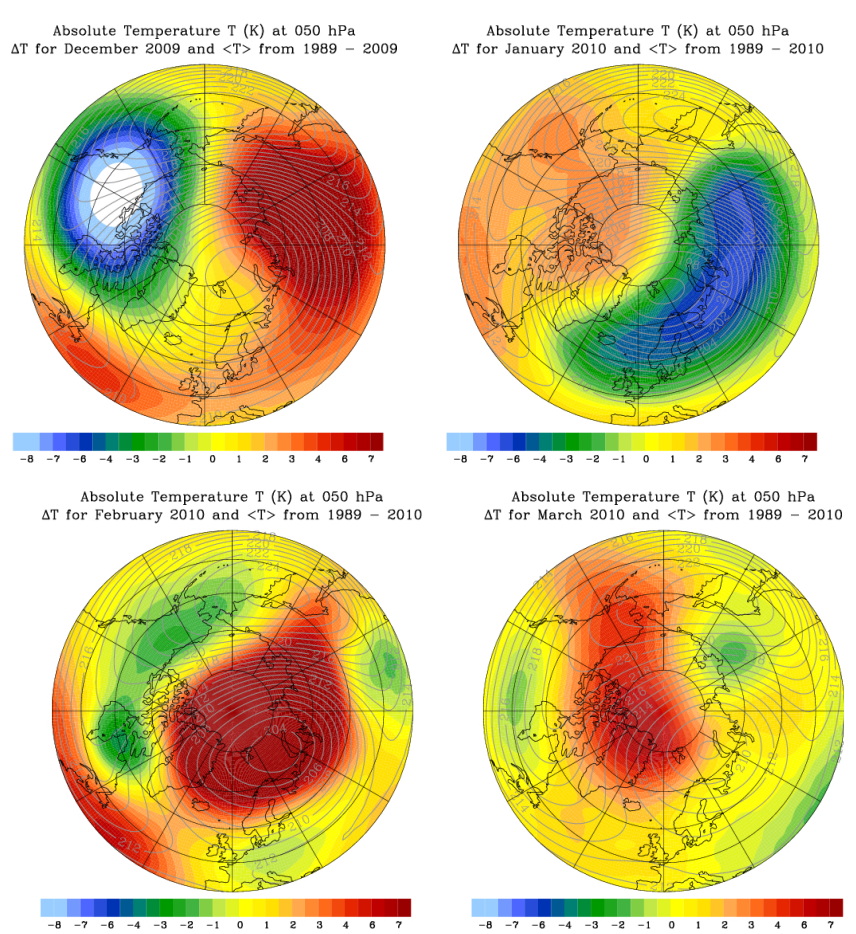

Fig. 6. Anomaly patterns of the absolute temperature (K; color shaded) and the monthly mean temperature ( $\mathrm{K}$; solid lines) at the $50 \mathrm{hPa}$ surface for December 2009, January, February, and March 2010, respectively. Data: ERA-Interim analyses interpolated on a regular $1 \times 1^{\circ}$ latitude/longitude grid.

Table 1. Monthly mean polar cap $\left(50\right.$ to $\left.90^{\circ} \mathrm{N}\right)$ temperatures $(\mathrm{K})$ at $30 \mathrm{hPa}$ calculated from the ERA-Interim data. Last two columns: winter means from November to February and December to February, respectively. Red (blue) colours denote unusually warm (cold) Arctic winter.

\begin{tabular}{ccccccc}
\hline Winter & Nov & Dec & Jan & Feb & NDJF & DJF \\
\hline $1989 / 1990$ & 210.677 & 206.686 & 207.556 & 216.460 & 210.345 & 212.571 \\
$1990 / 1991$ & 209.437 & 208.077 & 213.802 & 215.983 & 211.825 & 212.370 \\
$1991 / 1992$ & 209.401 & 208.523 & 214.181 & 215.521 & 211.906 & 212.241 \\
$1992 / 1993$ & 211.212 & 208.522 & 207.099 & 213.191 & 210.006 & 211.529 \\
$1993 / 1994$ & 210.584 & 210.759 & 212.366 & 211.931 & 211.410 & 211.301 \\
$1994 / 1995$ & 210.650 & 205.039 & 209.960 & 216.460 & 210.527 & 212.153 \\
$1995 / 1996$ & 209.493 & 203.882 & 206.729 & 210.934 & 207.760 & 208.811 \\
$1996 / 1997$ & 210.731 & 209.330 & 207.742 & 207.845 & 208.912 & 208.938 \\
$1997 / 1998$ & 209.215 & 211.510 & 212.547 & 214.574 & 211.961 & 212.468 \\
$1998 / 1999$ & 209.259 & 213.483 & 209.268 & 212.279 & 211.072 & 211.825 \\
$1999 / 2000$ & 208.426 & 206.466 & 205.583 & 211.830 & 208.076 & 209.638 \\
$2000 / 2001$ & 211.865 & 212.939 & 209.091 & 218.908 & 213.201 & 215.655 \\
$2001 / 2002$ & 208.673 & 211.560 & 214.141 & 214.429 & 212.201 & 212.272 \\
$2002 / 2003$ & 208.654 & 208.786 & 214.632 & 214.950 & 211.755 & 211.835 \\
$2003 / 2004$ & 209.550 & 210.723 & 215.200 & 212.540 & 212.003 & 211.338 \\
$2004 / 2005$ & 210.577 & 204.927 & 205.195 & 211.026 & 207.931 & 209.389 \\
$2005 / 2006$ & 210.514 & 208.535 & 215.574 & 213.876 & 212.125 & 211.700 \\
$2006 / 2007$ & 207.768 & 208.839 & 211.530 & 214.749 & 210.721 & 211.526 \\
$2007 / 2008$ & 210.160 & 206.310 & 209.313 & 216.015 & 210.449 & 212.125 \\
$2008 / 2009$ & 210.033 & 208.275 & 211.989 & 220.629 & 212.732 & 214.892 \\
$2009 / 2010$ & 212.599 & 210.022 & 208.875 & 218.695 & 212.548 & 215.003 \\
\hline MEAN & 209.975 & 208.723 & 210.416 & 214.654 & 210.927 & 211.885 \\
\hline
\end{tabular}


Table 2. Monthly mean polar cap $\left(50\right.$ to $\left.90^{\circ} \mathrm{N}\right)$ temperatures $(\mathrm{K})$ at $50 \mathrm{hPa}$ calculated from the ERA-Interim data. Last two columns: Winter means from November to February and December to February, respectively. Red (blue) colours denote unusually warm (cold) Arctic winter.

\begin{tabular}{ccccccc}
\hline Winter & Nov & Dec & Jan & Feb & NDJF & DJF \\
\hline $1989 / 1990$ & 212.140 & 208.599 & 208.247 & 214.767 & 210.938 & 212.568 \\
$1990 / 1991$ & 210.825 & 209.581 & 212.712 & 216.153 & 212.318 & 213.178 \\
$1991 / 1992$ & 211.283 & 209.673 & 213.153 & 214.852 & 212.240 & 212.665 \\
$1992 / 1993$ & 212.601 & 209.662 & 207.524 & 211.092 & 210.220 & 211.112 \\
$1993 / 1994$ & 212.378 & 211.974 & 212.739 & 212.322 & 212.353 & 212.249 \\
$1994 / 1995$ & 212.083 & 207.162 & 209.263 & 214.934 & 210.861 & 212.278 \\
$1995 / 1996$ & 211.591 & 206.898 & 207.450 & 210.050 & 208.997 & 209.647 \\
$1996 / 1997$ & 212.717 & 211.691 & 209.556 & 208.981 & 210.736 & 210.593 \\
$1997 / 1998$ & 211.244 & 212.444 & 213.319 & 214.126 & 212.783 & 212.985 \\
$1998 / 1999$ & 211.390 & 213.564 & 211.334 & 212.276 & 212.141 & 212.376 \\
$1999 / 2000$ & 210.623 & 208.584 & 206.527 & 210.619 & 209.088 & 210.111 \\
$2000 / 2001$ & 213.035 & 213.281 & 210.019 & 218.567 & 213.726 & 215.862 \\
$2001 / 2002$ & 210.693 & 211.824 & 214.385 & 214.364 & 212.816 & 212.811 \\
$2002 / 2003$ & 211.040 & 210.092 & 213.542 & 214.791 & 212.367 & 212.679 \\
$2003 / 2004$ & 211.555 & 211.307 & 215.177 & 214.479 & 213.129 & 212.955 \\
$2004 / 2005$ & 212.082 & 207.610 & 205.990 & 210.117 & 208.950 & 209.981 \\
$2005 / 2006$ & 211.971 & 210.146 & 214.778 & 215.848 & 213.185 & 213.453 \\
$2006 / 2007$ & 210.166 & 209.734 & 211.579 & 213.991 & 211.368 & 211.971 \\
$2007 / 2008$ & 212.208 & 208.745 & 209.572 & 214.865 & 211.347 & 212.671 \\
$2008 / 2009$ & 211.873 & 210.139 & 211.560 & 221.520 & 213.773 & 216.263 \\
$2009 / 2010$ & 214.335 & 211.312 & 209.902 & 217.921 & 213.368 & 215.372 \\
\hline MEAN & 211.802 & 210.191 & 210.711 & 214.237 & 211.748 & 212.561 \\
\hline
\end{tabular}

below $T_{\mathrm{NAT}}$, and even below $T_{\mathrm{FROST}}$ for a few days (Fig. 1). This period was the only occurrence of minimum vortex temperatures below $T_{\mathrm{NAT}}$ during the entire winter (Fig. 1). On two occasions between December and February, the zonal-mean zonal winds at $10 \mathrm{hPa}$ and $60^{\circ} \mathrm{N}$ strengthened markedly to over $40 \mathrm{~m} \mathrm{~s}^{-1}$ (Fig. 4b). The polar stratospheric cooling and vortex strengthening were likely a response of the weakened planetary wave activity which is indicated by the zonally-averaged meridional eddy heat flux decreasing well below its climatological average. Indeed, a period of anomalous low heat flux prevailed from mid-December to early January in similar manner as in the previous winter 2008/2009 (Fig. 8).

These two events when the polar stratosphere cooled and the vortex strengthened correspond to the development of a positive phase of the Western Pacific (WP) teleconnection pattern in the troposphere, as described by Orsolini et al. (2009) and Nishii et al. (2010). Generally, the Western Pacific pattern is characterized by a north-south oriented dipole of geopotential anomalies in the troposphere, with a high over the North Pacific in its positive phase. The WP typical development and influence on the stratospheric circulation is revealed by the composites of 18 strong events in the JRA re-analyses over the years 1979 to 2008 , as described in Nishii et al. (2010). It involves the westward retrogression of the high over the North Pacific, where it interacts and ultimately suppresses the climatological planetary wave trough over the Far East, giving rise to a decrease in upward wave fluxes into the stratosphere. In the composite analysis, the
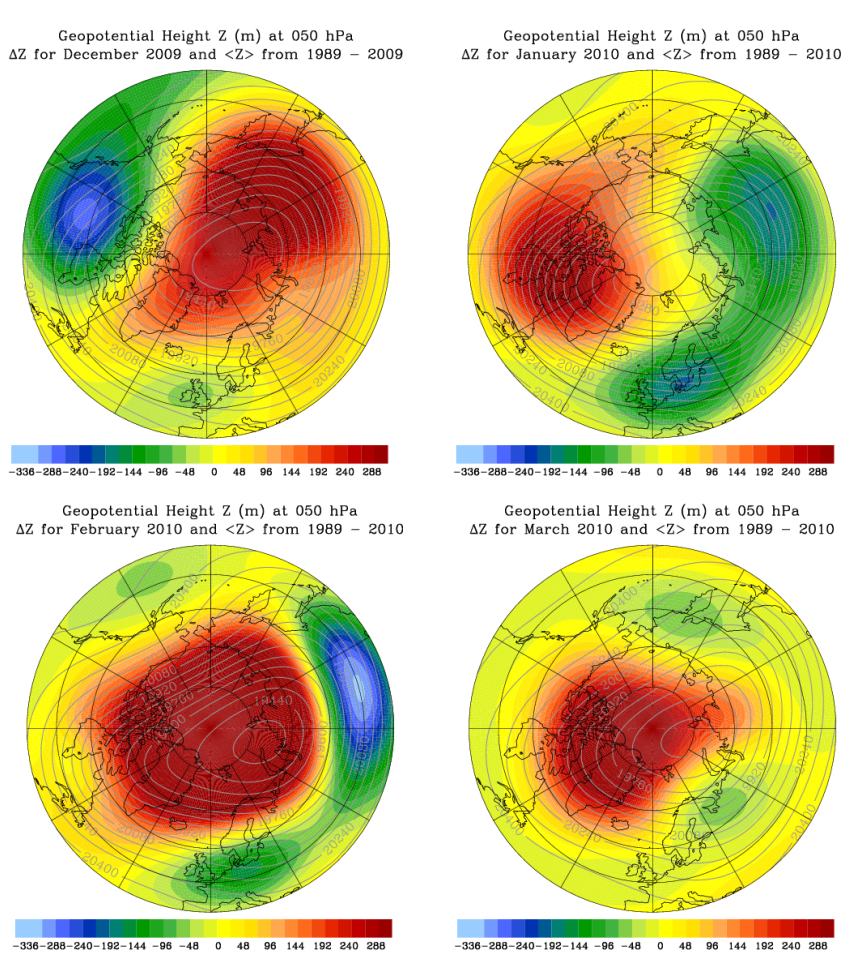

Fig. 7. Anomaly patterns of the geopotential height (m; color shaded) and the monthly mean geopotential height ( $\mathrm{m}$; solid lines) at the $50 \mathrm{hPa}$ surface for December 2009, January, February, and March 2010, respectively. Data: ERA-Interim analyses interpolated on a regular $1 \times 1^{\circ}$ latitude/longitude grid.

polar stratosphere cooled by up to $5 \mathrm{~K}$ on average at levels between $10 \mathrm{hPa}$ and $30 \mathrm{hPa}$ within 5 days of the peak of the WP event, and the cooling persisted for a month.

Calculation of a standardized WP index using an Empirical Orthogonal Function approach applied to the JRA reanalyses reveals that the period from December 2009 to early January 2010 was characterized by a positive WP index, with a first maximum occurring around 13 December and a second, stronger maximum around 3 January (Fig. 9). In agreement with the ECMWF data, the heat flux anomalies with respect to the 1980-2007 JRA climatology over mid and high latitudes were negative during this period, and the coldest 50$\mathrm{hPa}$ polar temperatures were found within a week of the peak in the WP index; see Figs. 8 and 9. Anomalously cold temperatures lasted slightly less than 3 weeks, before the return to anomalously warm temperatures; see Fig. 1.

Five-day averaged geopotential heights for 1-5 January and 6-10 January are shown in Fig. 10, at $250 \mathrm{hPa}$ and $30 \mathrm{hPa}$, separately, along with their anomalies from the 1980-2007 JRA climatology. In early January, a northsouth dipole anomaly exists at $250 \mathrm{hPa}$ over the North Pacific/Eastern Eurasia region that project strongly onto the WP pattern in its positive phase (Fig. 10a). Additionally, a prominent positive tropospheric height anomaly (blocking high) is located over southern Greenland leading to tropospheric as 


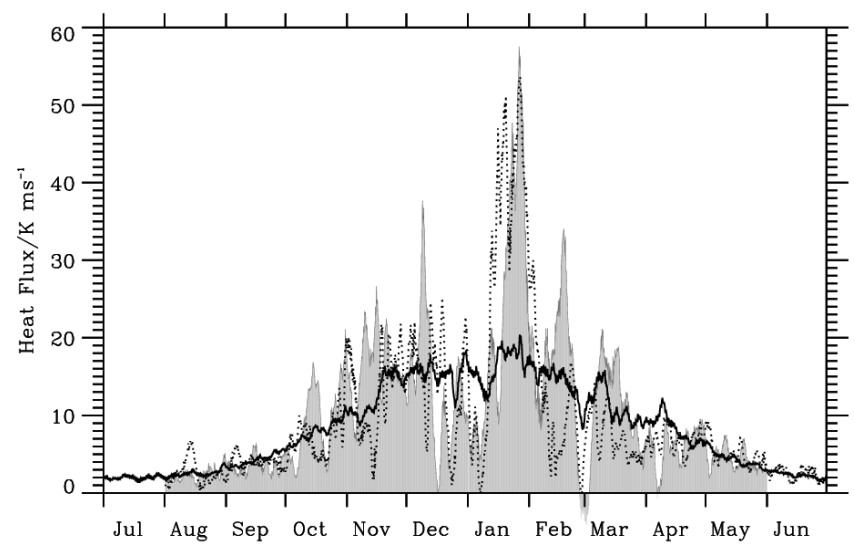

Fig. 8. Daily $100 \mathrm{hPa}$ zonally-averaged meridional heat flux as a function of time for the climatology (black line) and 2008/2009 (dotted line), and 2009-2010 (gray shading); compare to Fig. 5 in Hinssen and Ambaum (2010).

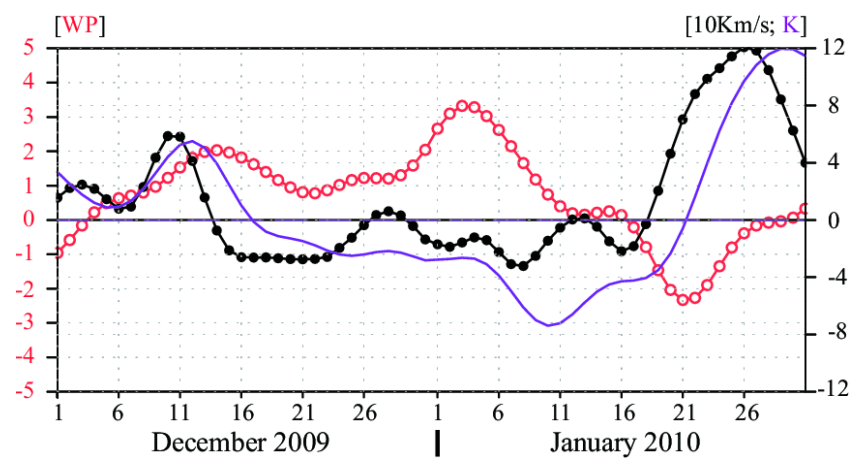

Fig. 9. Time series of the WP index (red; left axis), heat flux anomaly $\left([V \cdot T \cdot]_{\mathrm{a}}\right)$ from the 8-day low-pass filtered fields of meridional wind $(V)$ and temperature $(T)$ at the $100 \mathrm{hPa}$ surface (45 to $85^{\circ} \mathrm{N}$ mean, $10 \mathrm{~K} \mathrm{~m} \mathrm{~s}^{-1}$; black, right axis) as a measure of upward planetary wave propagation. Polar stratospheric temperature anomaly $T_{\mathrm{a}}$ at $50 \mathrm{hPa}$ (70 to $90^{\circ} \mathrm{N}$ mean, $\mathrm{K}$; purple, right axis). The anomalies are calculated with respect to the JRA 1979-2007 climatology.

well as stratospheric westerly winds. As they are nearly perpendicular to Greenland's east coast, the Atlantic block generated favourable flow conditions for the excitation and propagation of mountain waves; see Sect. 4. At stratospheric altitudes, the reinforcing polar vortex is still slightly elongated and shifted off the pole (Fig. 10b and compare to Fig. 2a).

From 6-10 January, following the peak in the WP index, the polar stratosphere at $30 \mathrm{hPa}$ is characterised by lower heights than normal and a strong zonal circulation (Fig. 10d). Such an anomaly, or in other words such a strong vortex event, is consistent with a damped planetary-wave-induced poleward heat flux as indicated in Figs. 8 and 9. The resulting reduction on the upward planetary wave flux by the positive WP pattern in early January 2010 might be partially offset by the influence of the prominent blocking high over (a)

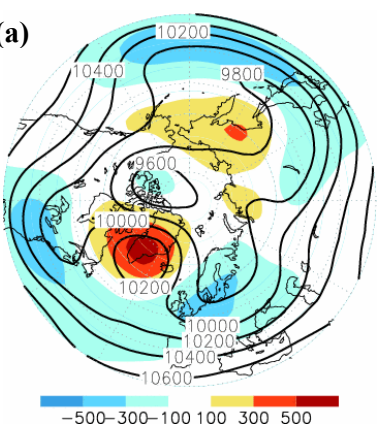

(b)

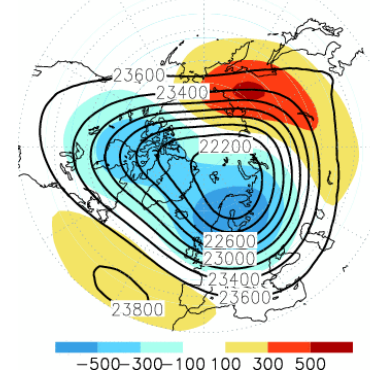

(c)

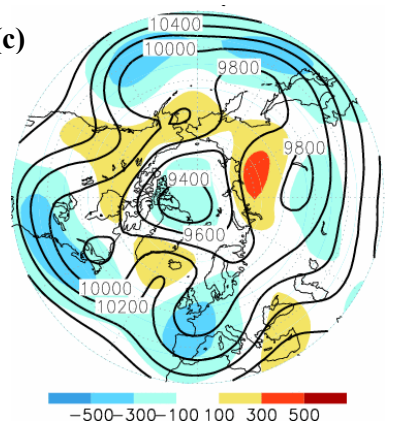

(d)

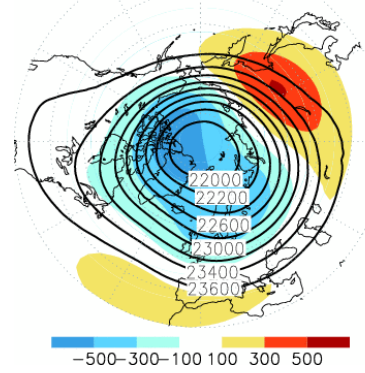

Fig. 10. Geopotential height ( $\mathrm{m}$; contour lines) and anomaly (m, colour shading) from its climatology (1980-2007) at $250 \mathrm{hPa}$ (a, c) and $30 \mathrm{hPa}(\mathbf{b}, \mathbf{d})$. (a, b) Average for 1-5 January 2010, (c, d) average for 6-10 January 2010.

the North Atlantic (Fig. 10c). The upward propagation of the planetary waves into the stratosphere tends to be weakened by blocking highs over the Far East and western North Pacific but enhanced by blocking highs over the Euro-Atlantic sector, see Nishii et al. (2011). In other words, the Arctic stratosphere would have been cooled even stronger if the Atlantic blocking had not formed simultaneously with the WP pattern; see Nishii et al. (2011).

The interaction of the Pacific blocking high with the planetary wave trough appears clearly in the evolution of the potential vorticity (PV) depicted at the $300 \mathrm{~K}$ isentropic surface from late December 2009 to early January 2010 in Fig. 11, where the PV $=2$ contour has been chosen to distinguish stratospheric $(\mathrm{PV}>2)$ from tropospheric air $(\mathrm{PV}<2)$. Over the Far East, the westward-propagating block leads to a strong inward and poleward planetary wave breaking extruding an elongated high-PV filament into mid-latitudes. A similar pattern was found in the composite diagnostics by Nishii et al. (2010). Planetary wave breaking is the essence of the developing blocking high over the western Pacific and Fig. 11 illustrates how the breaking weakened the trough over the Far East that is usually observed in winter seasons (Orsolini et al., 2009; Nishii et al., 2010).

Following this strong stratospheric cooling event, the transition to the major SSW came abruptly, without a preconditioning and weakening of the polar vortex (Fig. 4b; see also 

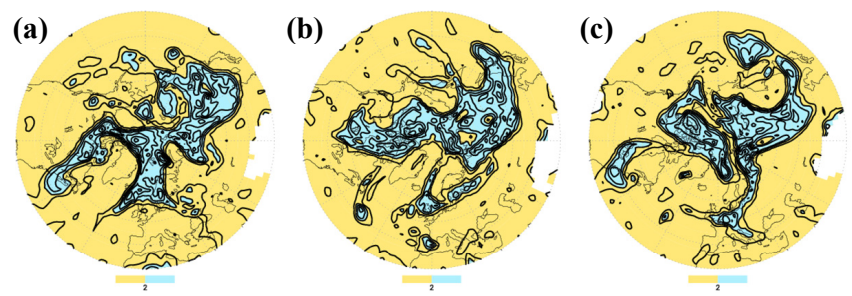

Fig. 11. Potential Vorticity (PVU, color shading) on $300 \mathrm{~K}$ potential temperature level. Yellow: PV less 2 PVU (tropospheric air), blue: PV larger 2 PVU (stratospheric air). (a) 30 December 2009; (b) 1 January 2010, (c) 3 January 2010.

Ayarzagüena et al., 2011). This particular SSW event was marked as an extreme positive anomaly of wave-activity injection into the stratosphere in referring to Figs. 8 and 9.

\section{Forecast quality}

Based on the operational analyses in association with the ERA-Interim climatology from 1989-2009, the research aircraft GEOPHYSIKA was deployed in anomalously cold stratospheric temperatures in January and under climatologically average conditions in March 2010 during the two phases of the RECONCILE campaign. During this campaign, operational forecasts were provided regularly to guide the operations of the GEOPHYSIKA. The flight planning for an aircraft operating in the stratosphere proceeds in successive steps starting about 5 to 6 days before take-off. Therefore, the medium-range forecasts of the ECMWF constituted a valuable tool for flight planning. During the daily weather briefings, the reliability of the operational deterministic forecasts was often discussed. Subjectively, the impression arose that the variability of the 6-10 day forecasts for the stratosphere was exceptionally high and that the ECMWF IFS predicted the SSW too early for longer lead times.

In order to quantify the variability of the IFS forecasts, we analysed the performance of the 50 members of the EPS for two different lead times during the winter 2009-2010. First, we consider the variability of the EPS forecasts before evaluating the forecast's skill. Figures 12 and 13 show time series of the SSW criteria $\Delta T$ and $U$ as well as the ensemble spreads, calculated as the standard deviations $\sigma_{\Delta T}$ and $\sigma_{U}$ (dotted lines in panels a and b) at $10 \mathrm{hPa}$ for forecast lead times of $240 \mathrm{~h}$ and $120 \mathrm{~h}$, respectively. Additionally, the false alarm and hit rates ${ }^{6}$ of the EPS are shown for the period from November 2009 till February 2010 (Figs. 12c and 13c).

\footnotetext{
${ }^{6}$ The false alarm rate is the ratio of false positive predictions to the sum of false positive and true negative predictions of the SSW criteria $\Delta T>0$ and $U<0$, respectively. The hit rate is the ratio of true positive predictions to the sum of true positive and false negative predictions of the SSW criteria $\Delta T>0$ and $U<0$, respectively.
}

(a)

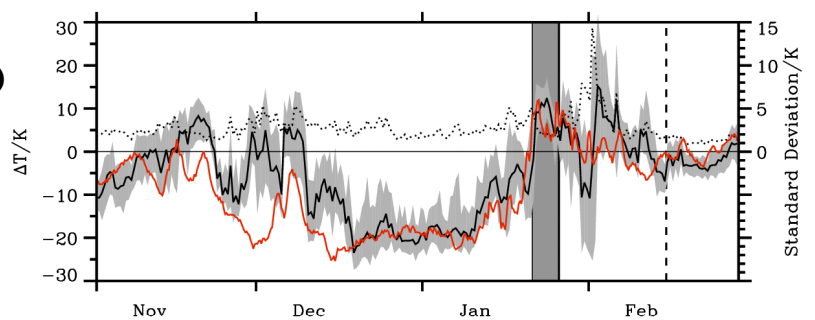

(b)

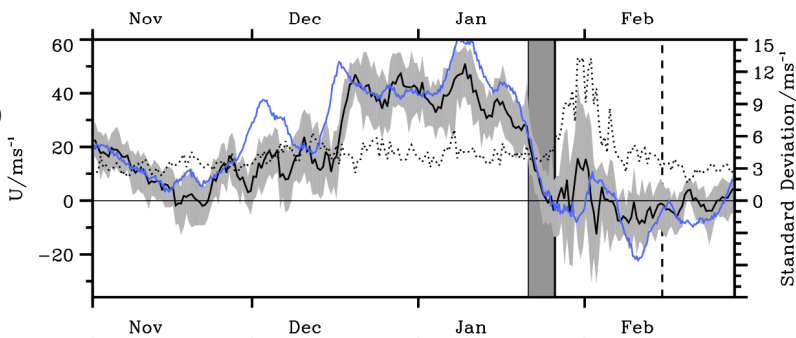

(c)

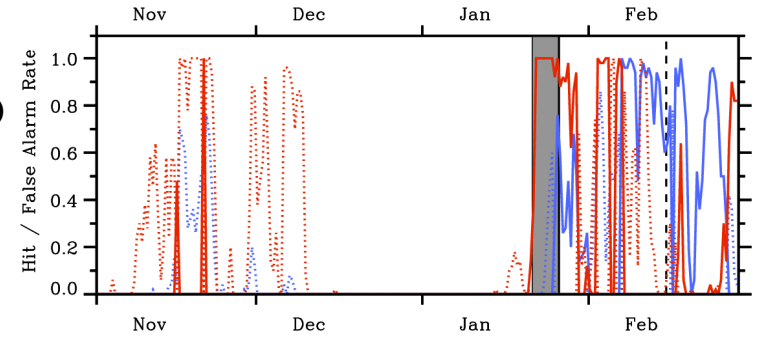

Fig. 12. Major warming criteria for a forecast lead time of $240 \mathrm{~h}$. (a) Meridional difference $\Delta T$ of the zonally averaged temperature between 85 and $60^{\circ} \mathrm{N}$ at $10 \mathrm{hPa}$. (b) Zonally averaged zonal wind $U$ at $60^{\circ} \mathrm{N}$ and $10 \mathrm{hPa}$. Red and blue lines in (a) and (b) denote the verifying analyses, respectively. The gray shaded area encloses the minimum and maximum values of all EPS members, the solid black line mark the ensemble mean, and the dotted lines the respective standard deviations $\sigma_{\Delta T}$ and $\sigma_{U}$ defined among the ensemble members around the corresponding ensemble means. (c) Hit rates (solid lines) and false alarm rates (dotted lines) assigned to the forecasted days of the EPS members satisfying the SSW criteria for $U$ (blue) and $\Delta T$ (red), respectively.

For both lead times, the ensemble spreads $\sigma_{\Delta T}$ and $\sigma_{U}$ are nearly uniform until the onset of the SSW. Typical values in this pre-SSW period are $\sigma_{\Delta T} \approx 3 \mathrm{~K}(0.8 \mathrm{~K})$ and $\sigma_{U} \approx$ $5 \mathrm{~m} \mathrm{~s}^{-1}\left(1 \mathrm{~m} \mathrm{~s}^{-1}\right)$ for the $240 \mathrm{~h}(120 \mathrm{~h})$ forecasts, respectively. As expected, the EPS spread decreases significantly for the shorter lead time in accordance with results by Jung and Leutbecher (2007), compare Figs. 12 and 13. During the SSW, $\sigma_{\Delta T}$ and $\sigma_{U}$ decrease or remain nearly the same whereas after the SSW the ensemble spreads increased by up to $500 \%$. This means, the forecasts containing the SSW period produce a larger uncertainty of flow regimes after the simulated SSW events occurred in the model simulations. Furthermore, the EPS forecasts also show a significant variability in the period of about 20 days after the central date of the SSW. Summarizing, the forecast spread is relatively smaller for forecasts that start before the vortex weakening. In contrast, it is larger for forecasts that start when the observed vortex is weakening (late January). This means, the 
(a)

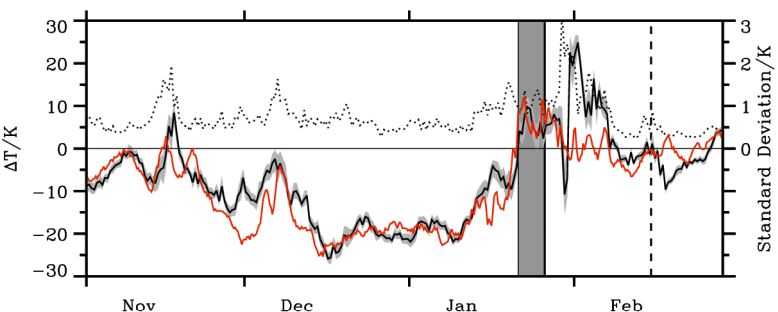

(b)

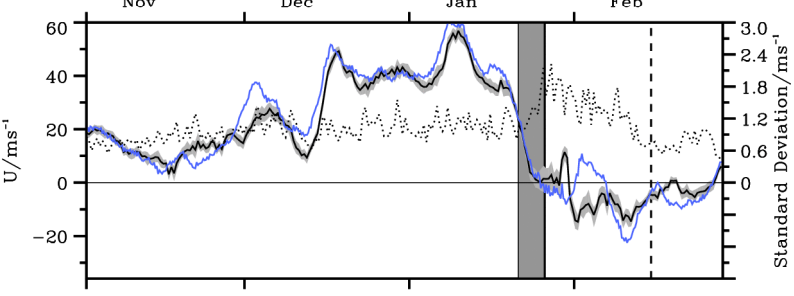

(c)

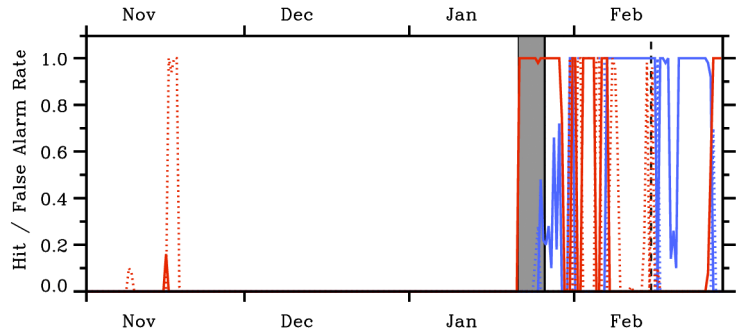

Fig. 13. Major warming criteria for a forecast lead time of $120 \mathrm{~h}$. (a) Meridional difference $\Delta T$ of the zonally averaged temperature between 85 and $60^{\circ} \mathrm{N}$ at $10 \mathrm{hPa}$. (b) Zonally averaged zonal wind $U$ at $60^{\circ} \mathrm{N}$ and $10 \mathrm{hPa}$. Red and blue lines in (a) and (b) denote the verifying analyses, respectively. The gray shaded area encloses the minimum and maximum values of all EPS members, the solid black line mark the ensemble mean, and the dotted lines the respective standard deviations $\sigma_{\Delta T}$ and $\sigma_{U}$ defined among the ensemble members around the corresponding ensemble means. (c) Hit rates (solid lines) and false alarm rates (dotted lines) assigned to the forecasted days of the EPS members satisfying the SSW criteria for $U$ (blue) and $\Delta T$ (red), respectively.

forecast system can capture well when the vortex begins to weaken, but it is difficult for the system to forecast how long the vortex weakening will last by using rapidly changing fields as initial values for the forecasts.

Surprising conclusions can be drawn from the analysis of the evolution of the hit and false alarm rates; see Figs. 12c and 13c. First of all, two distinct periods characterized either by high false alarm rates or high hit rates can be distinguished: the first period lasts from mid November until mid December 2009, and the second period covers the SSW. For a lead time of $240 \mathrm{~h}$, the false alarm rates for predicting a SSW in the first period are high, often equal to 1, i.e. all members of the EPS predict a positive $\Delta T$ between the polar cap and mid latitudes. For the U-criterion, the false alarm rates are smaller, i.e. a significant portion of the EPS members does not predict flow reversal. Recall that this period was characterized by higher than normal planetary wave activity (see Fig. 8), which might be responsible for the uncertainty in the
EPS forecasts. For shorter lead times, the EPS forecasts have higher skill and the false alarm rates are limited to shorter periods in November (Fig. 13c).

Turning the attention to the SSW period, all EPS members (hit rate $=1$ ) predict the onset and evolution of the SSW for the criteria $\Delta T>0$ very accurately, whereas about half of the members satisfy the criteria $U<0$. This surprisingly uniform performance of the EPS holds for both lead times. In this period, the ensemble mean follows very closely the verifying analyses and the false alarm rate is low. Prior to the SSW, the false alarm rate is small for both criteria and restricted to a short period before the central date of the SSW. In contrast, the period after the SSW is characterized by large uncertainty, with alternating periods of high hit rates and high false alarm rates.

A closer inspection of the time evolution of the ensemble means for a lead time of $240 \mathrm{~h}$ reveals nearly regular oscillations with a period of about 7 days in the forecast $\Delta T$ and $U$ fields. The reason for these oscillations remains unclear as they do not seem to be associated with the oscillations seen in the meridional heat flux. This leads to the question as to how realistic the forecasts are. Generally, the EPS members underestimate the strength of the polar vortex as the Uvalues of the operational analyses are almost always larger than the ensemble mean (the only exception is the SSW period). This may be a result of the reduced horizontal resolution of the EPS, as a comparison with Fig. 4b shows a satisfactory agreement between the U-values of the more highly resolved deterministic forecasts and the analyses.

In order to quantify the deviations between the $120 \mathrm{~h}$ and $240 \mathrm{~h}$ (EPS as well as deterministic) forecasts and the verifying analyses, we calculated the meridional temperature difference $\Delta T_{50}$ as zonally averaged temperature differences between the polar cap $\left(75\right.$ to $\left.90^{\circ} \mathrm{N}\right)$ and the mid-latitudes (50 to $65^{\circ} \mathrm{N}$ ) at $50 \mathrm{hPa}$ for NDJF, see Fig. 14. Except for minor deviations, the $\Delta T_{50}$ curves show the characteristic properties of the $\Delta T$ curves depicted in Figs. 12a and 13a for the respective lead time. As already indicated, the largest deviations $\left(\left|\Delta T_{50}\right|_{\max } \approx 10 \mathrm{~K}\right)$ between the forecasts and the verifying analyses occur in two periods from mid-November until mid-December 2009 and after the SSW in February 2010. This finding holds for both of the lead times considered (see Fig. 14c) and is in accordance with the high false alarm rates for the criterion $\Delta T>0$ during these periods. As above, enhanced planetary wave activity and incorrect flow responses of the model simulations to the stratospheric warming are possible causes. The high-resolution deterministic forecasts seem only to deviate from the EPS control run in periods of enhanced planetary wave activity. From mid-December 2009 until the end of January 2010, both forecasts are close together.

Finally, we turn to the predictability of the strong vortex events, which followed the high WP positive phases. At a lead time of $120 \mathrm{~h}$, the intensification of the negative meridional temperature gradient and of the jet strength are well 

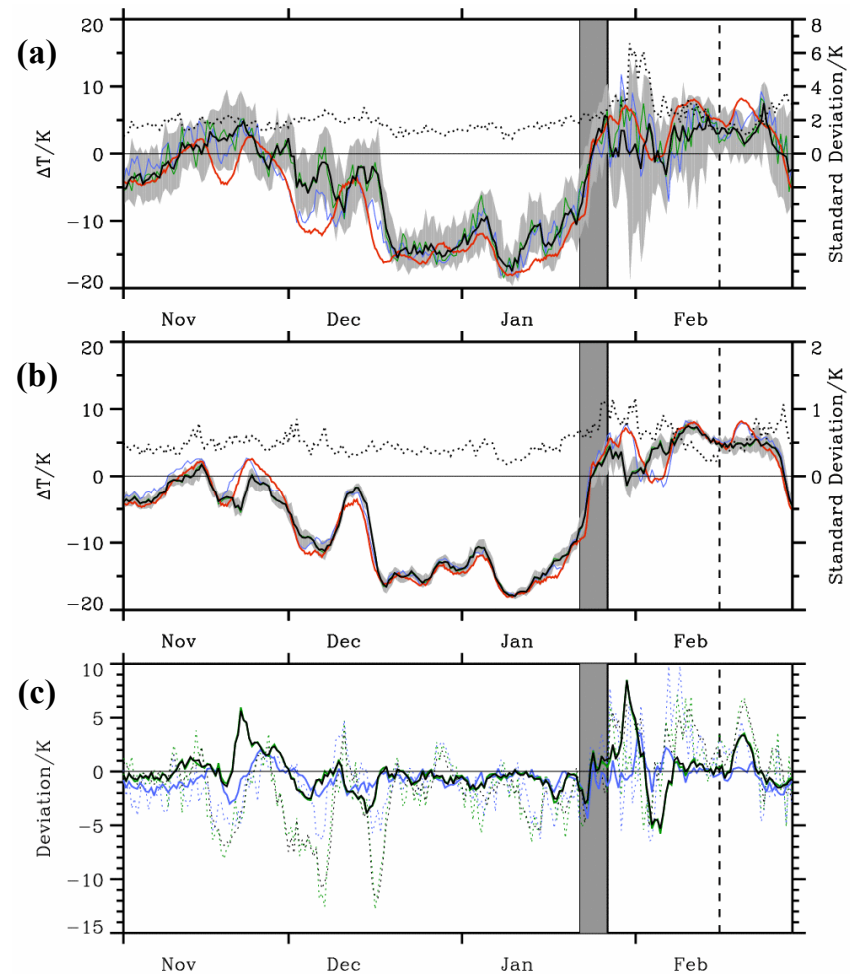

Fig. 14. Time series of $240 \mathrm{~h}$ (a) and $120 \mathrm{~h}$ (b) forecasts of the meridional temperature difference $\Delta T_{50}$ at $50 \mathrm{hPa}$ for the winter 2009-2010. Results are shown for high-resolution deterministic (blue solid), lower-resolution EPS control forecasts (green solid), and the ensemble mean (black solid). The area between the minima and maxima of $\Delta T_{50}$ from all 50 EPS members are shaded in grey. The dotted lines in the upper panels are the standard deviations of $\Delta T$ of the ensemble predictions. Also shown is the verifying operational analysis (red solid). The meridional temperature gradient $\Delta T_{50}$ is computed from zonally averaged differences between the polar cap $\left(75\right.$ to $\left.90^{\circ} \mathrm{N}\right)$ and the mid-latitudes $\left(50\right.$ to $\left.65^{\circ} \mathrm{N}\right)$. The bottom panel (c) shows the deviations between the verifying analyses and deterministic forecast (blue), the control forecast (green), and the ensemble mean (black), respectively. Solid lines are for the 5-day, dotted lines for the 10-day forecast. The grey shaded column marks the 5 day period after the mean temperature gradient between 85 and $60^{\circ} \mathrm{N}$ is positive and the vertical thick solid line marks the central date of the major warming event on 26 January 2010.

predicted in the EPS forecasts both at $50 \mathrm{hPa}$ (Fig. 14b) and $10 \mathrm{hPa}$ (Fig. 13a, b), with little spread among members. At the lead time of $240 \mathrm{~h}$, the second, strongest WP event in early January is well predicted, but the first event in December is predicted to occur a few days too late by nearly all members.

\section{Mountain wave-induced temperature anomalies}

As already indicated in Sect. 3.2, west winds dominated the tropospheric as well as stratospheric flow at the begin-
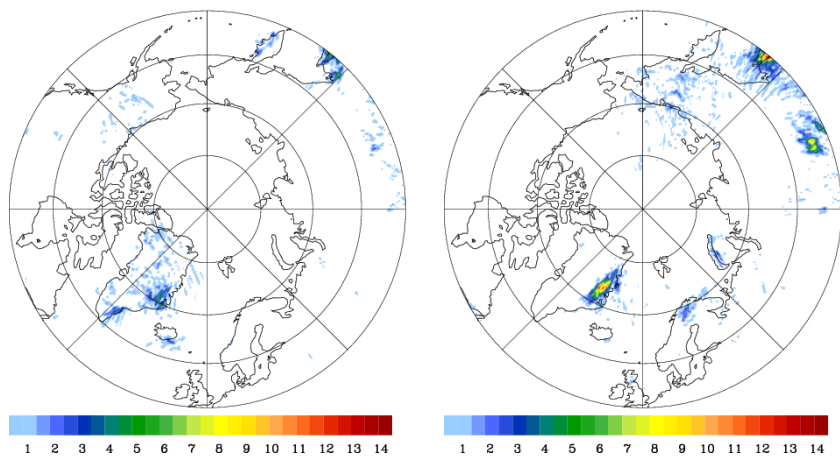

Fig. 15. Stratospheric gravity waves: locations of mountain wave occurrence (number of six-hourly events) as indicated by regions of $|\mathrm{DIV}|>2 \times 10^{-4} \mathrm{~s}^{-1}$ at $30 \mathrm{hPa}$ for October/November/December 2009 (left panel) and for January 2010 (right panel). Operational ECMWF analyses interpolated at a regular $0.5 \times 0.5^{\circ}$ latitude/longitude grid.

ning of January 2010. As shown in Dörnbrack and Leutbecher (2001), nearly unidirectional winds in the troposphere and stratosphere are one essential criterion for mountain waves propagating upward into the stratosphere. Indeed, besides synoptic-scale ice PSCs inside the cold polar vortex, CALIPSO frequently observed wave ice PSCs with distinct properties in backscatter ratio, aerosol depolarisation, and colour ratio during the exceptionally cold period in January 2010.

Pitts et al. (2011) found a reasonable agreement of the locations of these wave ice PSCs and extreme values of DIV for a limited period from 31 December 2009-14 January 2010. In a hydrostatic model such as the IFS, localized anomalies of the divergence above a certain threshold, e.g. $|\mathrm{DIV}|=2 \times 10^{-4} \mathrm{~s}^{-1}$ at $30 \mathrm{hPa}$, are suitable dynamical indicators of updrafts and downdrafts. Most of the events identified in early January 2010 could be directly linked to vertically propagating mountain waves as their geographical locations are in close proximity to steep orographic obstacles. Figure 15 (left panel) shows mountain wave events also occurring during the months October/November/December 2009. However, compared to the signature found in January 2010 (Fig. 15, right panel) their locations are more widespread and the frequency is smaller. Furthermore, there are no CALIPSO reports of wave ice PSCs during the months in 2009. If we accept the given threshold of the horizontal divergence as indicator of mountain waves, Greenland, northern Scandinavia, Iceland, and Novaya Zemlya can be identified as the most active locations for stratospheric mountain waves during the 2009-2010 winter.

Figure 16 shows CALIPSO observations of mountainwave induced PSCs over the east coast of Greenland on 4 January 2010 for two different orbit tracks, one parallel (Fig. 16a) and the other nearly perpendicular (Fig. 16b) to the coast line (see Supplement of Pitts et al., 2011 for plots 

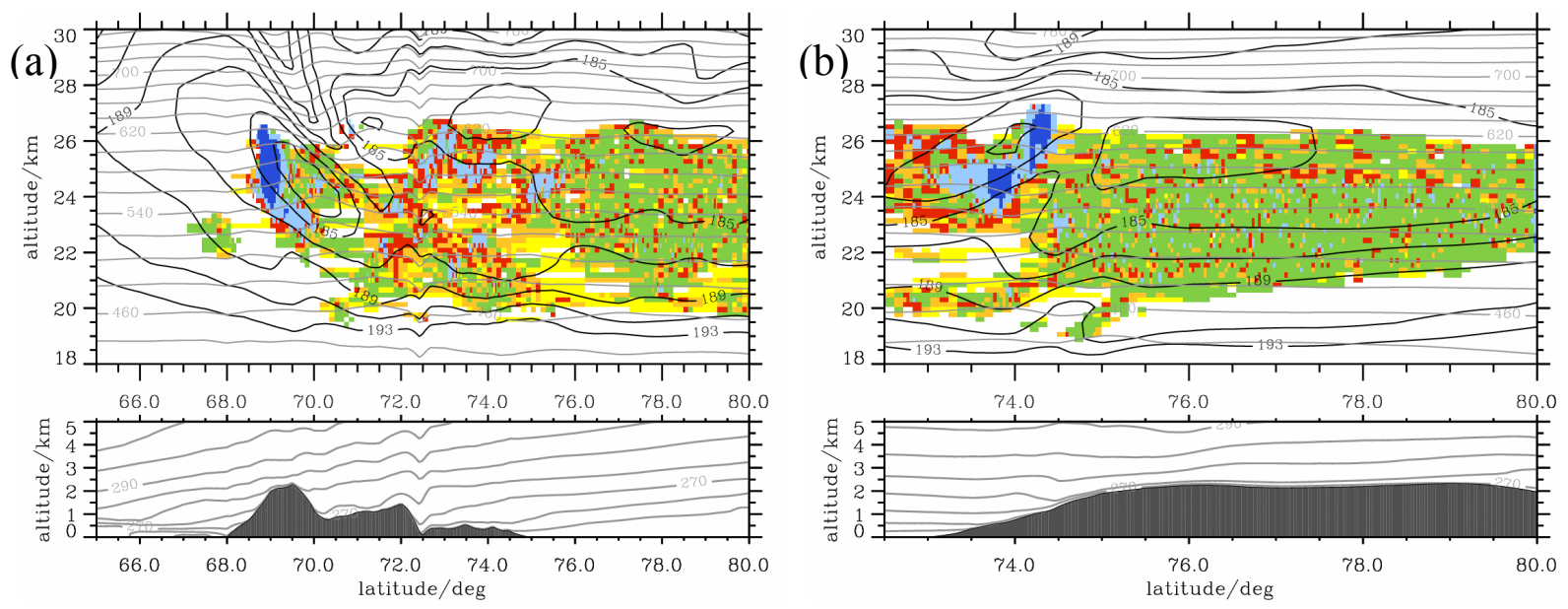

Fig. 16. Stratospheric gravity waves: CALIPSO PSC composition (blue: wave ice; light blue: ice, red: mixed 2 enhanced, orange: mixed 2; yellow: mixed 1; green: STS according to Pitts et al., 2011). ECMWF operational analyses interpolated at a regular $0.25 \times 0.25^{\circ}$ are superimposed: potential temperature (K, grey lines) and absolute temperature (K, black lines). (a) CALIPSO orbits at 05:03:43 UTC and (b) at 13:18:09 UTC on 4 January 2010.

of the orbit $\operatorname{tracks}^{7}$ ). The general wind direction is west, i.e. Fig. 16a shows PSC observations almost perpendicular and Fig. 16b observations nearly parallel to the prevailing westerly winds ${ }^{8}$. Superimposed are $\Theta$ and $T$ interpolated in space and time along the orbit tracks from the ECMWF operational analyses. Both the wavy structure in $\Theta$ and the tilted stratospheric temperature minimum as well as the vertically tilted coherent ice region reveal patterns of mountain waveinduced PSCs as observed over Scandinavia by airborne lidar (Dörnbrack et al., 2002). The PSC composition changed along the orbit track and along the main wind direction (wind is blowing from right to left in Fig. 16b): upstream the PSC was dominated by liquid STS clouds whereas NAT mixtures occur downstream of the ice PSCs. A similar composition change was also observed by airborne lidar measurements; see for example Fig. 10 in Dörnbrack et al. (2002). Figure 16a illustrates this finding along the south-north oriented cross-section parallel to Greenland's coastline. Depending on the distance of the track from the upstream mountains the composition changes from south to north: directly over the mountains ice clouds formed, further north and downstream from Greenland's mountains ice and NAT mixtures dominated whereas liquid STS clouds existed at the northernmost part of the orbit which was not influenced by the mountains of Greenland.

\footnotetext{
7 http://www.atmos-chem-phys.net/11/2161/2011/ acp-11-2161-2011-supplement.zip

8 It must be noted that both orbits are not completely aligned with the tropospheric and stratospheric winds which are nearly unidirectional in this period. Therefore, the mountain wave-induced temperature anomalies and undulations in potential temperature in Fig. 16 do not represent maximum possible values. Furthermore, a determination of the horizontal and vertical wavelengths is difficult.
}

In order to investigate the relationship between the divergence and the corresponding temperature fluctuations quantitatively, we consider the months of December 2009 and January 2010. A stratospheric box was defined to cover parts of Greenland from 60 to $85^{\circ} \mathrm{N}$ and 60 to $20^{\circ} \mathrm{W}$ and isentropic surfaces between $430 \mathrm{~K}$ and $610 \mathrm{~K}$. ECMWF operational analyses were interpolated to the isentropic surfaces on latitude/longitude grids with two different horizontal resolutions of $0.25^{\circ}$ and $2.50^{\circ}$, respectively. The time series of the minimum temperature $T_{\mathrm{MIN}}$ and the minimum/maximum horizontal divergence DIV $\mathrm{VIIN}_{\text {and }}$ DIV $\mathrm{V}_{\mathrm{MAX}}$ and the standard deviations ${ }^{9} \sigma_{\text {DIV }}$ and $\sigma_{T}$ in this particular domain are plotted for selected isentropic levels in Fig. 17. Periods of enhanced magnitude of DIV $\mathrm{MIN}_{\text {and }}$ DIV $\mathrm{VAX}_{\text {MA }}$ are associated with a temporal decrease in $T_{\mathrm{MIN}}$ and increased temperature standard deviations $\sigma_{T}$. Generally, the negative DIV $\mathrm{MIN}_{\mathrm{N}}$ values have a larger magnitude than the positive DIV $\mathrm{MAX}$ for both plotted resolutions. However, the magnitude of DIV $_{\text {MIN/MAX }}$ and $T_{\text {MIN }}$ is larger for the higher resolution of $0.25^{\circ}$. Especially in the period at the beginning of January 2010 , enhanced values of $\mid$ DIV $V_{\text {MIN/MAX }} \mid>2 \times 10^{-4} \mathrm{~s}^{-1}$ correspond to stratospheric temperature decreases associated with mountain wave induced cooling (compare the period around 4 January 2010 and Fig. 16). Based on these results, the period 2 to 4 January 2010 has been selected to study the relationship of DIV and $T$ in more detail as another mountain wave event of similar strength was also observed by CALIPSO on 2 January 2010, see Supplement in Pitts et al. (2011).

Figure 18a and $\mathrm{b}$ presents correlations between the minimum temperature $T_{\mathrm{MIN}}$ and the minimum and maximum

\footnotetext{
${ }^{9}$ Here, the standard deviation is defined spatially based on local deviations from the domain average.
} 

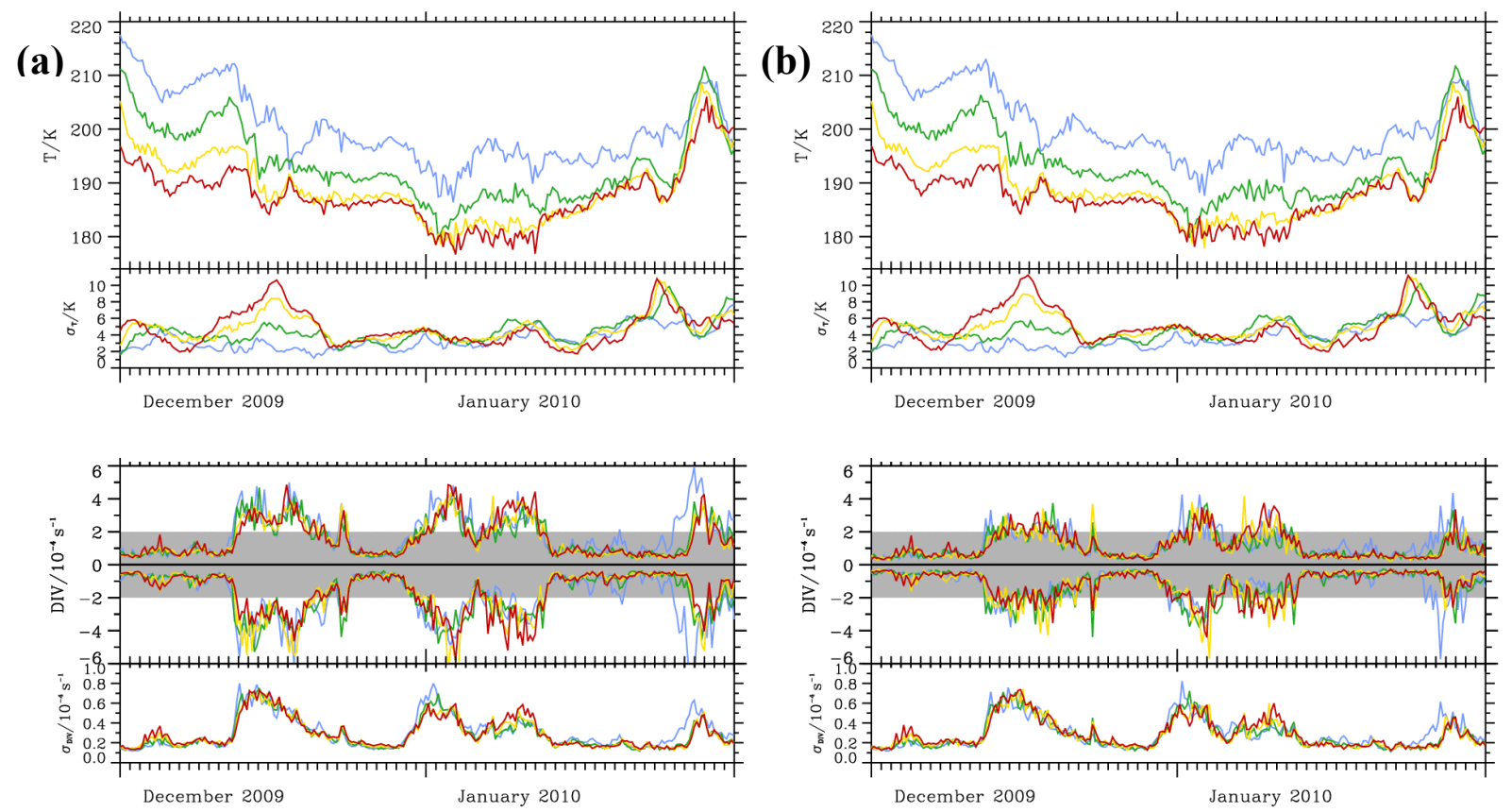

Fig. 17. Stratospheric gravity waves: top panels: $T_{\mathrm{MIN}}$ and standard deviations $\sigma_{T}(\mathrm{~K})$ above Greenland $\left(60\right.$ to $85^{\circ} \mathrm{N}$, 60 to $\left.20^{\circ} \mathrm{W}\right)$ at isentropic surfaces (colour coded: blue: $410 \mathrm{~K}$, green: $470 \mathrm{~K}$, yellow: $530 \mathrm{~K}$, red: $590 \mathrm{~K}$ ) for December 2009 and January 2010 . Bottom panels: same as above but for minimum and maximum horizontal divergence DIV $\mathrm{MIN}_{\text {and DIV }}$ MAX and the standard deviations $\sigma_{\mathrm{DIV}}$ $\left(\mathrm{s}^{-1}\right)$. The standard deviations $\sigma_{T}$ and $\sigma_{\mathrm{DIV}}$ are calculated spatially in the analysed domain. The gray shading encloses DIV values below the threshold used for identifying stratospheric gravity waves. ECMWF operational analyses interpolated at a regular $0.25 \times 0.25(\mathbf{a})$ and $2.50 \times 2.50^{\circ}$ (b) latitude/longitude grid, respectively.

horizontal divergences, DIV $\mathrm{VIN}_{\text {and }} \mathrm{DIV}_{\mathrm{MAX}}$ over Greenland for equidistantly distributed isentropic levels between $430 \mathrm{~K}$ and $610 \mathrm{~K}$ in the period from 2-4 January 2010 on two regular latitude/longitude grids with $2.50^{\circ}$ and $0.25^{\circ}$ resolution, respectively. As already indicated above, $T_{\mathrm{MIN}}$ reaches lower (more extreme) values at the higher resolved grid, especially, at the uppermost stratospheric levels. The magnitude of the correlation coefficients for the regression functions $T_{\mathrm{MIN}}=f\left(\mathrm{DIV}_{\mathrm{MIN}}\right)$ and $T_{\mathrm{MIN}}=f\left(\mathrm{DIV}_{\mathrm{MAX}}\right)$ increase from 0.34 and -0.27 for $2.50^{\circ}$ to 0.46 and -0.42 for $0.25^{\circ}$ resolution, respectively. Thus, there is a correlation between the minimum temperature and the magnitude of the divergence whereby $T_{\mathrm{MIN}}$ remains stronger correlated with DIV $_{\text {MIN }}$. The correlation between $T_{\text {MIN }}$ and DIV MIN/MAX can be increased in two ways: by restricting the analysis to upper stratospheric levels or by reducing the sample domain to the region where the mountains waves actually occurred. For example, if one only considers stratospheric levels between $570 \mathrm{~K}$ and $610 \mathrm{~K}$, the magnitudes of the correlation coefficients increase to 0.76 and -0.74 , respectively (not shown) whereas the domain reduction to an area between $60^{\circ} \mathrm{N}$ to $70^{\circ} \mathrm{N}, 40^{\circ} \mathrm{W}$ to $20^{\circ} \mathrm{W}$ results in an increase to 0.53 and -0.62 (see Fig. 18c).

Finally, Fig. 18d shows the same data for the reduced sample domain as in Fig. 18c but plotted for regional anomalies of the minimum temperature $T_{\mathrm{MIN}}$ and the ex- treme values of DIV: $\Delta T=T_{\mathrm{MIN}}-T_{\mathrm{AVE}}=f\left(\Delta \mathrm{DIV}^{-}\right)$and $\Delta T=f\left(\Delta \mathrm{DIV}^{+}\right)$with $\Delta \mathrm{DIV}^{-}=\mathrm{DIV}_{\mathrm{MIN}}-\mathrm{DIV}_{\mathrm{AVE}}$ and $\Delta \mathrm{DIV}^{+}=\mathrm{DIV}_{\mathrm{MAX}}-\mathrm{DIV}_{\mathrm{AVE}}$, where $\mathrm{DIV}_{\mathrm{AVE}}$ is the mean divergence in the sample domain. Here, the correlation coefficients are 0.54 and -0.82 , respectively. Therefore, extreme values of the magnitude of horizontal divergence $\mid$ DIV $_{\text {MIN/MAX }} \mid$ above a certain threshold (for example $2 \times$ $10^{-4} \mathrm{~s}^{-1}$ ) can serve as a suitable dynamical indicator of gravity wave-induced temperature anomalies in the stratosphere. Especially, Fig. 18d shows that the magnitude of the anomalies $\Delta T$ increases nearly linearly with growing $\left|\Delta \mathrm{DIV}^{ \pm}\right|$. The separation of points by isentropic levels found in panels (a)-(c) is due to the temperature decrease for increasing altitude. It disappears when we plot the anomalies $\Delta T$, and the random distribution of points demonstrates the irregular impact of gravity-wave induced cooling and warming in the height range under consideration (Fig. 18d).

Lagrangian forward and backward trajectories were calculated for the mountain wave event of 4 January 2010 over Greenland. Figure 19 shows the multiscale response of the altitude and temperature histories along the trajectories starting at $20 \mathrm{hPa}$ (Fig. 19a) and $40 \mathrm{hPa}$ (Fig. 19b) in the reduced sample region which covers that of the observed PSCs depicted in Fig. 16. As 4 January 2010 is approached, the parcels' temperatures decrease although there is no significant rise in altitude. This synoptic-scale cooling is due to 

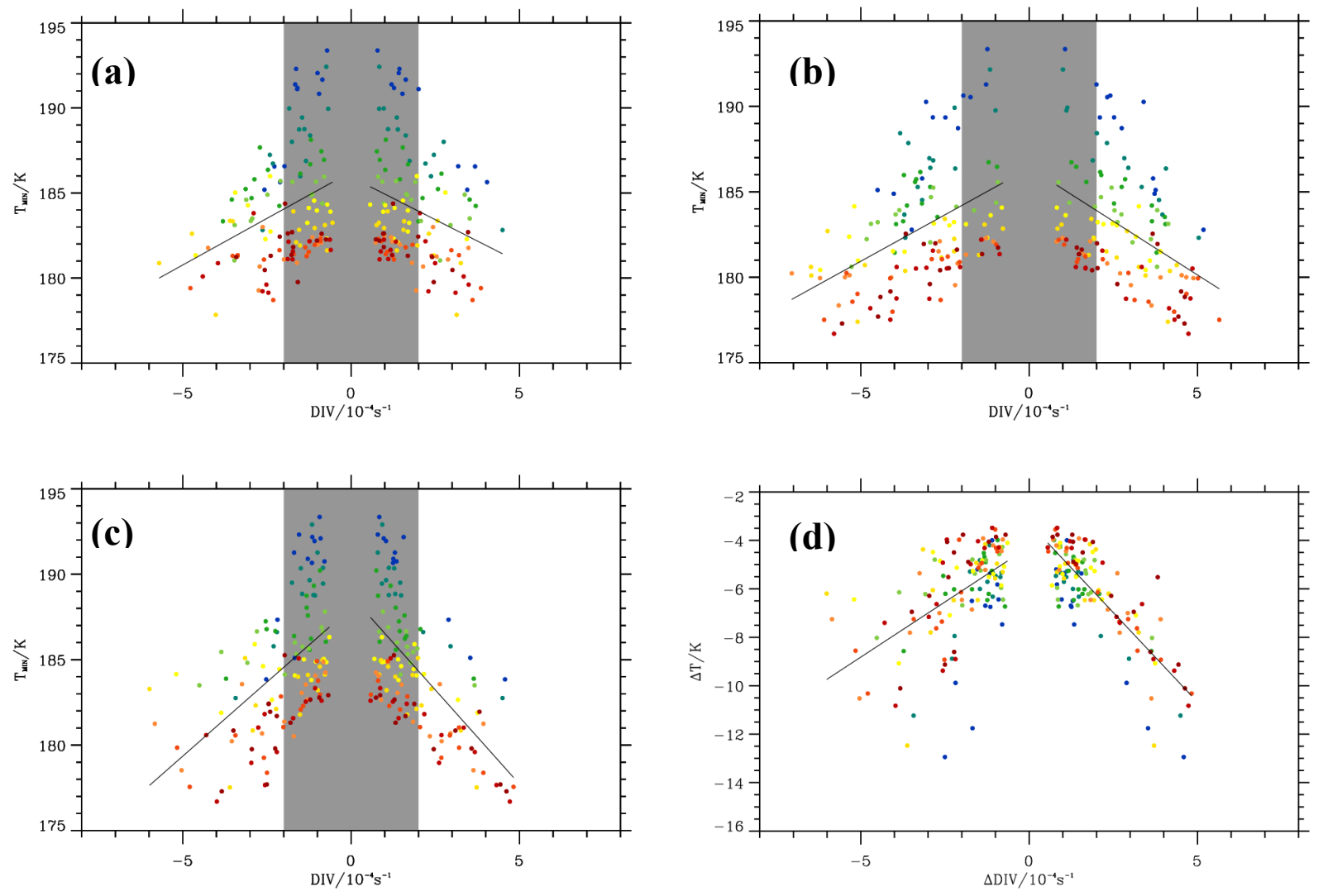

Fig. 18. Stratospheric gravity waves: correlation between the minimum temperature $T_{M I N}$ and DIV $V_{\text {MIN }}$ and DIV $V_{M A X}$ over Greenland (60 to $85^{\circ} \mathrm{N}, 60$ to $20^{\circ} \mathrm{W}$ ) for isentropic levels from $430 \mathrm{~K}, 450 \mathrm{~K}, \ldots, 610 \mathrm{~K}$ (from blue to red) in the period 2 to 4 January 2010 . ECMWF operational analyses interpolated at a regular $2.50 \times 2.50^{\circ}$ (a) and $0.25 \times 0.25^{\circ}$ (b) latitude/longitude grid, respectively. The correlation coefficients $T_{\mathrm{MIN}}=f\left(\mathrm{DIV}_{\mathrm{MIN}}\right)$ and $T_{\mathrm{MIN}}=f\left(\mathrm{DIV}_{\mathrm{MAX}}\right)$ amount to 0.34 and -0.27 for (a) and 0.46 and -0.42 for (b). Panel (c): same data as for (b) taken from a limited domain at the east coast of Greenland (60 to $70^{\circ} \mathrm{N}, 40$ to $20^{\circ} \mathrm{W}$ ); here, the correlation coefficients amount to 0.53 and -0.62 . Panel (d): same data as in panel (c) but for $\Delta T=T_{\mathrm{MIN}}-T_{\mathrm{AVE}}=f\left(\Delta \mathrm{DIV}^{-}\right)$and $\Delta T=f\left(\Delta \mathrm{DIV}^{+}\right)$with $\Delta \mathrm{DIV}^{-}=\mathrm{DIV}_{\mathrm{MIN}}-\mathrm{DIV}_{\mathrm{AVE}}$ and $\Delta \mathrm{DIV}^{+}=\mathrm{DIV}_{\mathrm{MAX}}-\mathrm{DIV}_{\mathrm{AVE}}$. Here, the correlation coefficients amount to 0.54 and -0.82.

the cold area of the polar vortex the parcels gradually approach. Additionally, mountain wave-induced cooling and warming and the associated displacements in the parcels' altitudes are the most prominent features over the east coast of Greenland on 4 January 2010. The ensemble of trajectories as a whole undergoes vertical oscillations with an amplitude of about $2000 \mathrm{~m}$. These vertical displacements of the air parcels lead to enhanced heating and cooling rates reaching up to $\pm 7 \mathrm{~K} \mathrm{~h}^{-1}$ in this period. The minimum temperature attains extreme values, here, especially for the trajectories released at $20 \mathrm{hPa}$. Altogether, the structure of the temperature fluctuations changes from the time before the gravity wave event to the time after. In the mean, the maximum and minimum heating and cooling rates show larger magnitudes after the wave event. This means, disturbances due to the wave event propagate with the mean wind and might impact the PSC formation/evolution downstream.

\section{Conclusions}

The EC funded project RECONCILE explored essential physical and chemical processes for improving the predictability of Arctic stratospheric ozone loss by means of an aircraft field experiment during the Arctic winter 20092010. The campaign forecasts for the research flights into the stratosphere as well as the post-campaign analyses of the in-situ and remote-sensing observations inspired most of the topics investigated in this paper.

Here, we overview and document the evolution of the Arctic polar vortex employing high resolution operational ECMWF analyses. We found that the stratospheric winter evolved in different phases: planetary wave disturbances in November/early December prohibited a quick early cooling and kept the minimum stratospheric temperatures well above the climatological mean. After a vortex split in early December, the formation of a strong and cold polar vortex dominated the evolution from mid-December 2009 to the end of January 2010. It was shown that the formation of this 

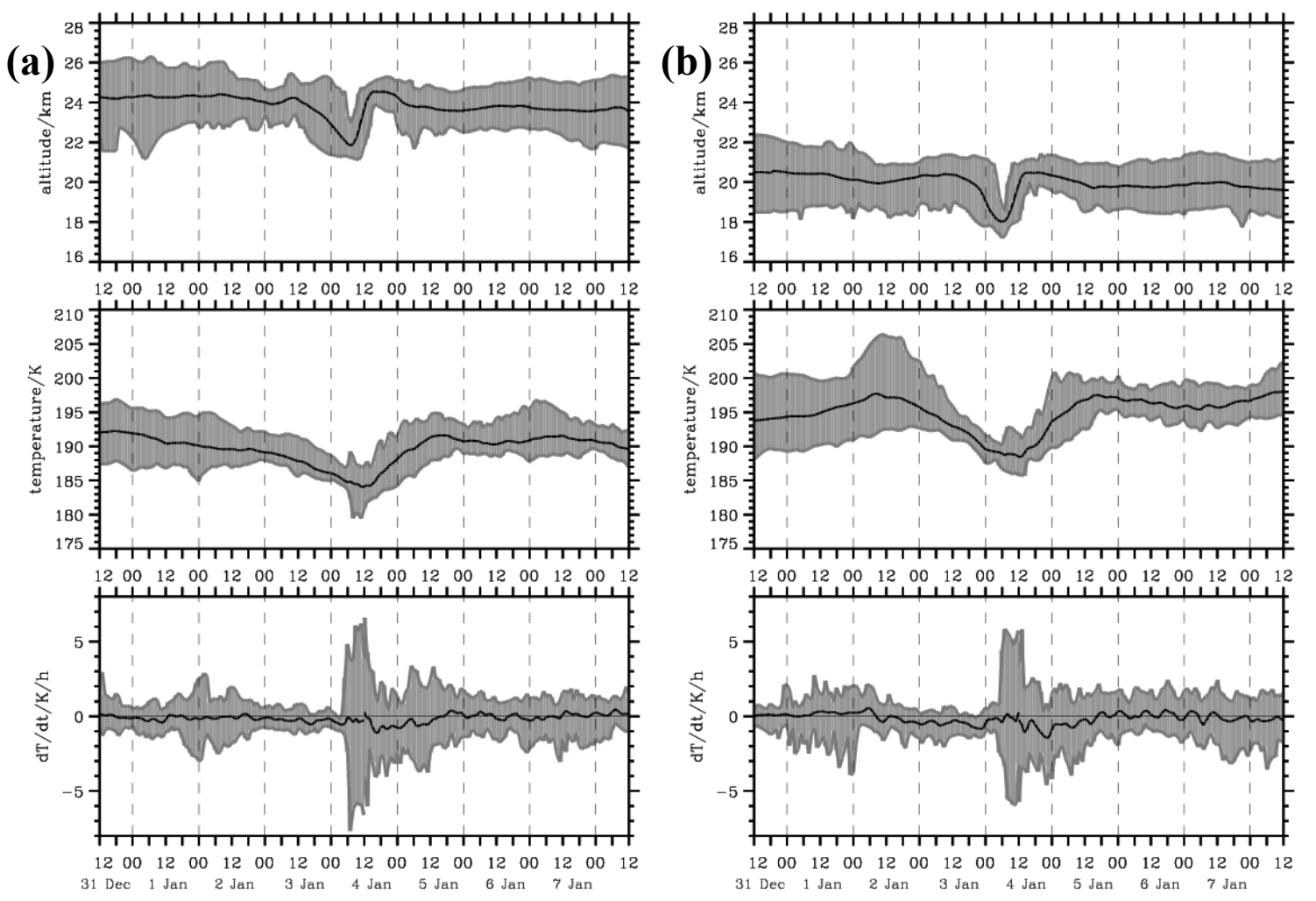

Fig. 19. Stratospheric gravity waves: time series of selected quantities of forward and backward trajectories launched at $20 \mathrm{hPa}$ (a) and $40 \mathrm{hPa}(\mathbf{b})$ on a $1 \times 1^{\circ}$ latitude/longitude grid between 68 to $75^{\circ} \mathrm{N}$ and 30 to $20^{\circ} \mathrm{W}$ on 4 January 2010 12:00 UTC. Maximum and minimum values of the ensemble of all trajectories enclose the gray-shaded area of parcels altitude (top row), absolute temperature (middle row), and heating and cooling rate (bottom row. The thick black lines denote the mean value of the respective quantities for the trajectory ensemble.

exceptionally cold and strong mid-winter polar vortex could be traced back to the intensification of the WP teleconnection pattern. A major SSW marked the end of the cold period. After being markedly displaced from the pole, the vortex eventually split into two lobes, with one lobe surviving until midMarch 2010 when the second phase of RECONCILE campaign concluded. A climatological analysis revealed that the 2009-2010 winter was one of the warmest overall winters in the last $21 \mathrm{yr}$. Only the period from the end of December 2009 until the end of January 2010 was colder than the climatological mean.

For the first time, the ensemble prediction system has been analysed to investigate the forecast skill of the ECMWF IFS. It was shown that the $240 \mathrm{~h}$ forecasts provide a reliable means to predict the onset and the process of the SSW. The false alarm rate was low and almost all members of the ensemble predicted the correct evolution (high hit rate). However, after the warming happened, the ensemble predictions deviated significantly leading to a high ensemble spread. In accordance with the findings of Jung and Leutbecher (2007), we also found a remarkable reduction of ensemble spread for a reduced lead time of $120 \mathrm{~h}$.

During mid-winter, especially in January 2010, wave ice PSCs were frequently identified in the CALIPSO measure- ments. Here, a typical CALIPSO observation of a mountainwave event over Greenland was analysed in more detail. The currently available spatial resolution of about $16 \mathrm{~km}$ provided by the operational ECMWF numerical weather prediction model IFS ${ }^{10}$ allows estimates of the temperature anomalies, cooling rates and their persistence downstream of the mountains for resolved gravity waves with horizontal wavelengths larger than about $100 \mathrm{~km}$. In particular, a correlation between stratospheric temperature anomalies and the magnitude of the horizontal divergence could be derived. It was shown that the magnitude of the divergence is directly proportional to the temperature anomaly in a limited area surrounding the resolved mountain waves.

The authors are aware that the different topics presented in this paper have not been completely explored and that all possible details have not been elaborated. Each of the topics investigated could be the subject of a research paper on its own. For example, to elucidate the contributions of the

10 This horizontal resolution of an operational global model amounts approximately to the resolution which was used for studying regional mesoscale effects on the dynamics and chemistry of the polar vortex some years ago, see Carslaw et al. (1998), Dörnbrack et al. (1998), and Eckermann et al. (2006). 
different planetary wave numbers to the stratospheric warming event and its subsequent evolution more precisely could be one topic to be explored. More case studies relating the magnitude of the horizontal divergence field to stratospheric temperature anomalies could lead to simple parameterizations of gravity-wave induced impacts on particle formation for use in global circulation models. Nevertheless, we think that this paper might be a useful reference for all those who participated in the RECONCILE campaign and those who are interested in the different subjects of the paper.

\section{Supplementary material related to this article is available online at: http://www.atmos-chem-phys.net/12/ 3659/2012/acp-12-3659-2012-supplement.zip.}

Acknowledgements. The field activities in Kiruna, as well as the meteorological support and analysis, were funded by the EC as part of the FP7 project RECONCILE (Grant number: RECONCILE226365-FP7-ENV-2008-1. We thank Hal Maring, NASA Radiation Sciences Program manager, and David Considine, NASA Program Scientist for the CALIPSO/CloudSat Missions for their continued support of CALIPSO PSC research (MP, LP). Support for L. Poole is provided under NASA contract NNL11AA00B. The ECMWF data were available through the special project "Effect of nonhydrostatic gravity waves on the stratosphere above Scandinavia" by one of the authors (A.D.).

Edited by: F. Khosrawi

\section{References}

Andrews, D. G., Holton, J. R., and Leovy, C. B.: Middle Atmosphere Dynamics, Academic Press, 489 pp., 1987.

Ayarzagüena, B., Langematz, U., and Serrano, E.: Tropospheric forcing of the stratosphere: A comparative study of the two different major stratospheric warmings in 2009 and 2010, J. Geophys. Res., 116, D18114, doi:10.1029/2010JD015023, 2011.

Carslaw, K. S., Wirth, M., Tsias, A., Luo, B. P., Dörnbrack, A., Volkert, A., Leutbecher, M., Renger, W., Bacmeister, J. T., Reimer, E., and Peter, T.: Increased stratospheric ozone depletion due to mountain-induced atmospheric waves, Nature, 391, 675-678, 1998.

Charlton, A. J. and Polvani, L. M.: A new look at stratospheric sudden warmings. Part I: Climatology and modeling benchmarks, J. Climate, 20, 449-469, 2007.

Cohen, J., Foster, J., Barlow, M., Saito, K., and Jones, J.: Winter 2009-2010: A case study of an extreme Arctic Oscillation event, Geophys. Res. Lett., 37, L17707, doi:10.1029/2010GL044256, 2010.

Dee, D. P., Uppala, S. M., Simmons, A. J., Berrisford, P., Poli, P., Kobayashi, S., Andrae, U., Balmaseda, M. A., Balsamo, G., Bauer, P., Bechtold, P., Beljaars, A. C. M., van de Berg, L., Bidlot, J., Bormann, N., Delsol, C., Dragani, R., Fuentes, M., Geer, A. J., Haimberger, L., Healy, S. B., Hersbach, H., Hólm, E. V., Isaksen, L., Kållberg, P., Köhler, M., Matricardi, M., McNally, A. P., Monge-Sanz, B. M., Morcrette, J.-J., Park, B.-K., Peubey,
C., de Rosnay, P., Tavolato, C., Thépaut, J.-N., and Vitart, F.: The ERA-Interim reanalysis: configuration and performance of the data assimilation system, Q. J. Roy. Meteor. Soc., 137, 553597, doi:10.1002/qj.828, 2011.

Dörnbrack, A. and Leutbecher, M.: Relevance of mountain waves for the formation of polar stratospheric clouds over Scandinavia: A 20 year climatology, J. Geophys. Res., 106, 1583-1593, 2001.

Dörnbrack, A., Leutbecher, M., Volkert, H., and Wirth, M.: Mesoscale forecasts of stratospheric mountain waves, Meteorol. Appl., 5, 117-126, 1998.

Dörnbrack, A., Birner, T., Fix, A., Flentje, H., Meister, A., Schmid, H., Browell, E. V., and Mahoney, M. J.: Evidence for inertia gravity waves forming polar stratospheric clouds over Scandinavia, J. Geophys. Res., 107, 8287, doi:10.1029/2001JD000452, 2002.

Eckermann, S. D., Dörnbrack, A., Vosper, S. B., Flentje, H., Mahoney, M. J., Bui, T. P., and Carslaw, K. S.: Mountain waveinduced polar stratospheric cloud forecasts for aircraft science flights during SOLVE/THESEO 2000, Weather Forecast., 21, 42-68, 2006.

Hanson, D. and Mauersberger, K.: Laboratory studies of the nitric acid trihydrate: Implications for the south polar stratosphere, Geophys. Res. Lett., 15, 855-858, 1988.

Hinssen, Y. B. L. and Ambaum, M. H. P.: Relation between the 100 $\mathrm{hPa}$ heat fux and stratospheric potential vorticity, J. Atmos. Sci., 67, 4017-4027, 2010.

Hortal, M.: The development and testing of a new two-timelevel semi-Lagrangian scheme (SETTLS) in the ECMWF forecast model, Q. J. Roy. Meteor. Soc., 128, 1671-1687, doi: 10.1002/qj.200212858314, 2002.

Hunt, W. H, Winker, D. M., Vaughan, M. A., Powell, K. A., Lucker, P. L., and Weimer, C.: CALIPSO Lidar Description and Performance Assessment, J. Atmos. Ocean. Tech., 26, 1214-1228, doi:10.1175/2009JTECHA1223.1, 2009.

Jung, T. and Leutbecher, M.: Performance of the ECMWF forecasting system in the Arctic during winter, Q. J. Roy. Meteor. Soc., 133, 1327-1340, 2007.

Khosrawi, F., Urban, J., Pitts, M. C., Voelger, P., Achtert, P., Kaphlanov, M., Santee, M. L., Manney, G. L., Murtagh, D., and Fricke, K.-H.: Denitrification and polar stratospheric cloud formation during the Arctic winter 2009/2010, Atmos. Chem. Phys., 11, 8471-8487, doi:10.5194/acp-11-8471-2011, 2011.

Krüger, K., Naujokat, B., and Labitzke, K.: The Unusual Midwinter Warming in the Southern Hemisphere Stratosphere 2002: A Comparison to Northern Hemisphere Phenomena, J. Atmos. Sci., 62, 603-613, doi:10.1175/JAS-3316.1, 2005.

Kuttippurath, J., Godin-Beekmann, S., Lefèvre, F., and Goutail, F.: Spatial, temporal, and vertical variability of polar stratospheric ozone loss in the Arctic winters 2004/2005-2009/2010, Atmos. Chem. Phys., 10, 9915-9930, doi:10.5194/acp-10-9915-2010, 2010.

Lait, L. R.: An alternative form for potential vorticity, J. Atmos. Sci., 51, 1754-1759, 1994.

Limpasuvan, V., Thompson, D. W. J., and Hartmann, D. L.: The Life Cycle of the Northern Hemisphere Sudden Stratospheric Warmings, J. Climate, 17, 2584-2596, 2004.

Liu, Z., Vaughan, M. A., Winker, D. M., Hostetler, C. A., Poole, L. R., Hlavka, D., Hart, W., and McGill, M.: Use of probability distribution functions for discriminating between cloud and 
aerosol in lidar backscatter data, J. Geophys. Res., 109, D15202, doi:10.1029/2004JD004732, 2004.

Nishii, K., Nakamura, H., and Orsolini, Y. J.: Cooling of the wintertime Arctic stratosphere induced by the Western Pacific teleconnection pattern, Geophys. Res. Lett., 37, L13805, doi:10.1029/2010GL043551, 2010.

Nishii, K., Nakamura, H., and Orsolini, Y. J.: Geographical dependence observed in blocking high influence on the stratospheric variability through enhancement and suppression of upward planetary-wave propagation, J. Climate, 24, 6408-6423, doi:10.1175/JCLI-D-10-05021.1, 2011.

Onogi K., Tsutsui, J., Koide, H., Sakamoto, M., Kobayashi, S., Hatsushika, H., Matsumoto, T., Yamazaki, N., Kamahori, H., Takahashi, K., Kadokura, S., Wada, K., Kato, K., Oyama, R., Ose, T., Mannoji, N., and Taira, R.: The JRA-25 reanalysis, J. Meteorol. Soc. Jpn., 85, 369-432, 2007.

Orsolini, Y. J., Karpechko, A. Y., and Nikulin, G.: Variability of the Northern Hemisphere polar stratospheric cloud potential: The role of North Pacific disturbances, Q. J. Roy. Meteor. Soc., 135, 1020-1029, doi:10.1002/qj.409, 2009.

Pitts, M. C., Thomason, L. W., Poole, L. R., and Winker, D. M.: Characterization of Polar Stratospheric Clouds with spaceborne lidar: CALIPSO and the 2006 Antarctic season, Atmos. Chem. Phys., 7, 5207-5228, doi:10.5194/acp-7-5207-2007, 2007.

Pitts, M. C., Poole, L. R., and Thomason, L. W.: CALIPSO polar stratospheric cloud observations: second-generation detection algorithm and composition discrimination, Atmos. Chem. Phys., 9, 7577-7589, doi:10.5194/acp-9-7577-2009, 2009.

Pitts, M. C., Poole, L. R., Dörnbrack, A., and Thomason, L. W.: The 2009-2010 Arctic polar stratospheric cloud season: a CALIPSO perspective, Atmos. Chem. Phys., 11, 2161-2177, doi:10.5194/acp-11-2161-2011, 2011.
Plougonven, R., Teitelbaum, H., and Zeitlin, V.: Inertia gravity wave generation by the tropospheric midlatitude jet as given by the Fronts and Atlantic Storm-Track Experiment radio soundings, J. Geophys. Res., 108, 4686, doi:10.1029/2003JD003535, 2003.

Powell, K. A., Hostetler, C. A., Liu, Z., Vaughan, M. A., Kuehn, R. E., Hunt, W. H., Lee, K., Trepte, C. R., Rogers, R. R., Young, S. A., and Winker, D. M.: CALIPSO Lidar Calibration Algorithms: Part I - Nighttime $532 \mathrm{~nm}$ Parallel Channel and $532 \mathrm{~nm}$ Perpendicular Channel, J. Atmos. Ocean. Tech., 26, 2015-2033, doi:10.1175/2009JTECHA1242.1, 2009.

Stefanutti, L., Sokolov, L., Balestri, S., MacKenzie, A. R., and Khattatov, V.: The M-55 Geophysica as a platform for the airborne polar experiment, J. Atmos. Ocean. Tech., 16, 1303-1312, 1999.

Untch, A. and Hortal, M.: A finite-element scheme for the vertical discretization of the semi-Lagrangian version of the ECMWF forecast model, Q. J. Roy. Meteor. Soc., 130, 1505-1530, doi:10.1256/qj.03.173, 2004.

Wang, L. and Chen, W.: Downward Arctic Oscillation signal associated with moderate weak stratospheric polar vortex and the cold December 2009, Geophys. Res. Lett., 37, L09707, doi:10.1029/2010GL042659, 2010.

Wernli, H. and Davies, H. C.: A lagrangian-based analysis of extratropical cyclones. I: The method and some applications, Q. J. Roy. Meteor. Soc., 123, 1677-1706, 1997. 